\title{
Investigating the archaeointensity determination success of prehistoric ceramics through a multidisciplinary approach: new and re-evaluated data from Greek collections
}

\author{
D. Kondopoulou, ${ }^{1}$ M. Gómez-Paccard, ${ }^{2}$ E. Aidona, ${ }^{1}$ Ch. Rathossi, ${ }^{3}$ C. Carvallo, ${ }^{4}$ \\ E. Tema, ${ }^{5}$ K.G. Efthimiadis ${ }^{6}$ and G.S. Polymeris ${ }^{7}$ \\ ${ }^{1}$ Department of Geophysics, School of Geology, Aristotle University of Thessaloniki, 54124 Thessaloniki, Greece. E-mail: despi@geo.auth.gr \\ ${ }^{2}$ Instituto de Geociencias IGEO (CSIC, UCM), Ciudad Universitaria, E-28040 Madrid, Spain \\ ${ }^{3}$ Sector of Earth Materials, Department of Geology, University of Patras, Rio Patra 26504, Greece \\ ${ }^{4}$ Institut de Minéralogie, de Physique des Matériaux, et de Cosmochimie (IMPMC), UPMC, UMR CNRS 7590, MNHN, IRD UMR 206, 4 Place Jussieu, \\ F-75005 Paris, France. \\ ${ }^{5}$ Dipartimento di Scienze della Terra, Università degli Studi di Torino, via Valperga 35, I-10125 Torino, Italy \\ ${ }^{6}$ School of Physics, Aristotle University of Thessaloniki, 54124 Thessaloniki, Greece \\ ${ }^{7}$ Institute of Nuclear Sciences, University of Ankara, 06100 Beşevler, Ankara, Turkey
}

Accepted 2017 May 22. Received 2017 May 3; in original form 2016 June 28

\section{SUMMAR Y}

The Balkan area provides an almost continuous record of the geomagnetic field variations during the last eight millennia but important data dispersion and chronological gaps are still observed. In order to improve this pattern, we oriented our research towards the study of Greek prehistoric ceramics and pottery collections. We present here new archaeointensity and mineralogical results from pottery and ceramics collected in two Bronze Age sites in Northern Greece, corresponding to the middle third and middle second millennium BC. Thermal demagnetization experiments, thermomagnetic curves, thermal demagnetization measurements of three axes composite isothermal magnetization and first-order reversal curves (FORC) diagrams were performed in order to define the main magnetic carriers and select the most promising samples for archaeointensity determination. The results suggest that the majority of the studied materials are dominated by a mixture of superparamagnetic and stable single domain grains, with very little magnetic interactions. In almost all samples the main magnetic carrier observed is a low coercivity mineral, most probably magnetite and/or Ti-magnetite. Classical Thellier experiments, including both the thermoremanent magnetization anisotropy and cooling rate corrections were performed on the selected samples. Two new archaeointensities were obtained and compared with previous data available for Greece and neighbouring countries and with global geomagnetic field models results. In order to investigate the causes of the high rate of failure observed in our archaeointensity experiments, we re-examined the results obtained from the study of four collections already published by better characterizing the magnetic and mineralogical properties of the studied fragments. Specific hysteresis curves performed at different layers of ceramic fragments reveal an important degree of inhomogeneity. Mineralogical analysis of selected samples from the totality of six Greek prehistoric sites studied, including new X-ray powder diffraction analysis and a detailed description of the different geological contexts, is provided. The results suggest that the sherds were all fired in medium-high temperatures (mostly between $500^{\circ}$ and $800^{\circ} \mathrm{C}$ ). The nature of the baked clay paste in response to the local geology appears to account for a part of the variability in magnetic properties. We suggest that X-ray powder diffraction analyses and thorough examination of the geological environment in combination with a satisfactory knowledge of the corresponding excavations history might provide an additional tool to appropriately select pottery fragments before performing future archaeointensity experiments.

Key words: Europe; Archaeomagnetism; Magnetic field variations through time; Palaeointensity. 


\section{INTRODUCTION}

In the last 15 years, great progress on archaeomagnetic research has been achieved both in Europe and worldwide (Brown et al. 2015 and references therein). As a consequence, our knowledge about the variation of the Earth's magnetic field in the past has greatly improved. For example, new evidence of short-lived regional maxima intensity episodes has been recently recovered but the spatial and temporal variation of these features is still poorly understood (e.g. Shaar et al. 2011; de Groot et al. 2013; Genevey et al. 2016; Gómez-Paccard et al. 2016). One of the most important constraints for the accurate description of the geomagnetic field strength evolution in the past is the absence of continuous records due to the limited availability of well-dated archaeological material suitable for archaeointensity determinations. The Balkan area, due to its rich archaeological heritage, provides a unique opportunity to recover an almost continuous reconstruction of the full geomagnetic field vector during the last millennia. Balkan archaeomagnetic studies started in the late 1960s with the work of Mary Kovacheva (Kovacheva 1969). Since then, a considerable amount of both directional and intensity data have been added (see Kovacheva et al. 2014 for a recent compilation). In Greece, systematic archaeomagnetic investigations started about 10 yr later (see Tema \& Kondopoulou 2011 and De Marco et al. 2008, 2014 for a review), although the first data were published before, by Belshé et al. (1963). Together with some results from Serbia and South Hungary, the Bulgarian and Greek data provide an almost continuous reconstruction of the full geomagnetic field vector variations in the Balkan area for the last 8000 years. However, the temporal distribution of the Balkan data is still uneven and several issues regarding the reliability of some of the published Greek archaeointensity data have been outlined (De Marco et al. 2008; Tema \& Kondopoulou 2011; Gómez-Paccard et al. 2012a; Tema et al. 2012). For instance, the scarcity of archaeomagnetic data from the fourth millennium BC is due to several occupation gaps attested in many sites of Greece, especially Northern Greece, as well as in Bulgaria (Maniatis 2014 and references therein; Tsirtsoni 2016). This gap is partly bridged in Southern Thasos Island where settlements covering the second half of the fourth millennium $\mathrm{BC}$ have been excavated and dated (Maniatis et al. 2015). Two other major features may be observed for the prehistoric period in the Balkans: the uneven temporal distribution of the data during the entire Bronze age (third and second millennium BC) and the systematically lower Greek archaeointensities, in comparison with the Bulgarian ones, for the Late sixth to the Late third millennium BC (Tema \& Kondopoulou 2011). Contrary to Bulgaria, where the considerable amount of prehistoric data was obtained only from 'in situ' structures, Greek data for this period come almost exclusively from ceramics and pottery. Such collections are abundant in Greece and are very often well studied as far as their clay characteristics are concerned and also accurately dated (e.g. Reingruber \& Thissen 2009; Nodarou 2010; Hein \& Kilikoglou 2012; Wardle et al. 2014; Urem-Kotsou 2016, among others).

In an effort to elucidate these questions, we focus on this period and present here the archaeomagnetic study of several ceramic fragments collected from two archaeological sites located in Northern Greece (red stars in Fig. 1), corresponding to the Middle and Late Bronze Age: Skala Sotiros (SKO) and Apsalos (APK), respectively. The new archaeointensity data obtained, together with a revision of previously published data from Greece, provide new insights on geomagnetic field intensity changes during prehistoric times. Moreover, and in order to further investigate the causes of the high rate of failure observed in the archaeointensity experiments per- formed, we also present an extensive mineralogical characterization of both successful and failed samples through first-order reversal curves (FORC) diagrams, hysteresis curves and optical X-ray powder diffraction (XRPD) analysis. Selected Greek potteries from four previously studied prehistoric sites (blue stars in Fig. 1a) are also re-examined through the same approach. Additionally, we favoured an extended geological introduction to the archaeological studied sites. The knowledge of local geology is of paramount importance for the petrographic study of ceramics since the cross-examination of the clay paste and geological formations allows the localization of potential sources for the raw materials used. Altogether, the mineralogical and geological data provide further information on the firing conditions of the studied ceramics and offer new potential for successful selection of pottery characteristics before using them for archaeointensity determination.

\section{ARCHAEOLOGICAL AND GEOLOGICAL CONTEXT, DATING AND SAMPLES DESCRIPTION}

The two studied sites, APK and SKO, are situated in Northern Greece (Fig. 1a) but belong to different geological and archaeological contexts. Their main features related to both aspects are given below:

The APK archaeological site is situated in the Vardar zone and Almopias subzone, which is constituted by alluvial deposits overlying Mesozoic flysch and Mio-Pliocene volcanoclastic formations and volcanic tuffs. Intense volcanism during the Early Quaternary resulted in the emplacement of several volcanic centres. During the construction of a new road in the late nineties, two archaeological sites were reported and excavated near the village of Apsalos, one corresponding to the Middle Neolithic and the other to the Late Bronze Age. Within the Bronze Age settlement an almost intact ceramic kiln, several depositories and abundant ceramic fragments documented the existence of a workshop area. The findings within the kiln were matt-painted and engraved sherds. A total of 11 independent fragments, 5 from the sherds and 6 from the baked clays found within the kiln from the collapsed roof (Fig. 1b, APK samples) were selected for archaeomagnetic analysis. All fragments were dark red and medium grained. In order to define the kiln's age, two radiocarbon datings have been performed by the excavator at Demokritos Archaeometry Laboratory, Athens. The analysed samples were a carbonated peg immediately north of the kiln's entrance with code number DEM-1145 and a carbon piece within a pit, at the side of the kiln and code number DEM-1149 (Chrysostomou et al. 2002 and Maniatis, personal communication, 2016). The ${ }^{14} \mathrm{C}$ ages were calibrated using the Oxcal 4.2. online software (http://calib.qub.ac.uk/calib/) and the INTCAL13 curve (Reimer et al. 2013). Both uncalibrated and calibrated results are given in Table 1. The Chronomodel model (http://www.chronomodel.fr) was used to synthesize the interval time ranges for the beginning, the occupation and the end of the site (Lanos et al. 2015; Lanos \& Philippe 2015, 2017). According to well-established archaeological constraints (Chrysostomou et al. 2002; Maniatis, personal communication, 2016), the pottery fragments studied here for archaeointensity experiments can be ascribed to the abandonment of the APK archaeological site and therefore we retain the age range associated to the end of this phase [1511-1202 yr BC, 95 per cent level of confidence], obtained with the Chronomodel software. Due to the kiln's typology, this phase cannot be younger than $1300 \mathrm{yr}$ BC (A. Georgiadou, personal communication, 2016) therefore we 

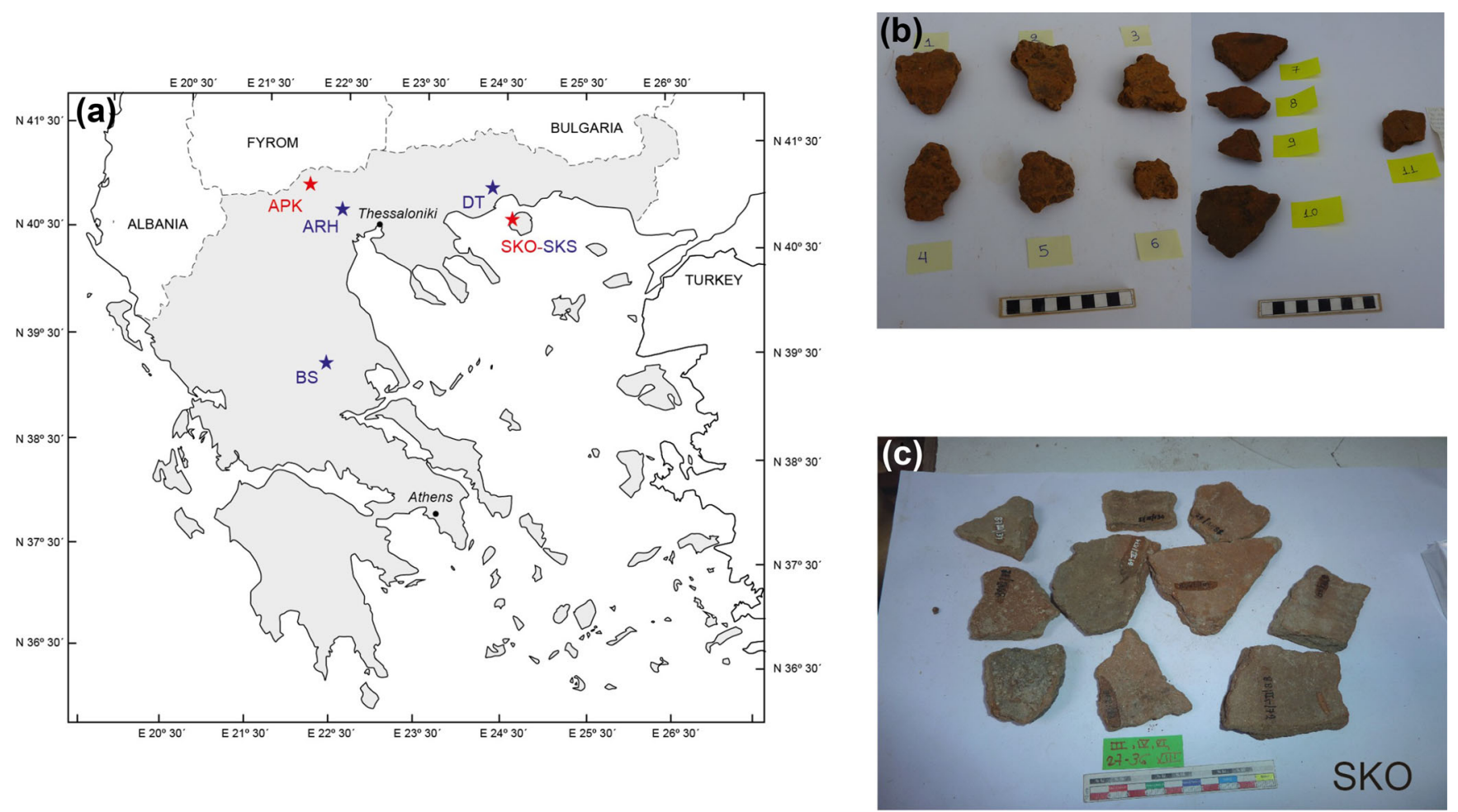

Figure 1. (a) Location map of the new sites APK and SKO (red stars) and the previously studied ones ARH, BS, DT, SKS (blue stars). (b) The ceramic collection from APK. Numbers 1-6 correspond to baked clays from the collapsed roof and 7-11 to sherds. (c) The representative group from SKO.

Table 1. Radiocarbon results available for the studied sites (see text for details). The ${ }^{14} \mathrm{C}$ ages were calibrated using the Oxcal 4.2 online software (http://calib.qub.ac.uk/calib/) and the INTCAL13 curve (Reimer et al. 2013).

\begin{tabular}{lcc}
\hline Lab Code & Age BP & $\begin{array}{c}\text { Calibrated Age BC } \\
(95 \% \text { level of confidence })\end{array}$ \\
\hline DEM-1145 (APK) & $3128 \pm 30$ & {$[-1491,-1298]$} \\
DEM-1149 (APK) & $3170 \pm 30$ & {$[-1502,-1399]$} \\
DEM-1852 (SKS) & $3595 \pm 30$ & {$[-2025,-1886]$} \\
DEM-1743 (SKS) & $3638 \pm 30$ & {$[-2130,-1917]$} \\
DEM-1742 (SKS) & $3562 \pm 35$ & {$[-2019,-1774]$} \\
DEM-103-84 (SKO) & $3840 \pm 50$ & {$[-2463,-2146]$} \\
DEM-106-87 (SKO) & $3840 \pm 40$ & {$[-2459,-2154]$} \\
DEM-105-86 (SKO) & $3838 \pm 40$ & {$[-2459,-2153]$} \\
\hline
\end{tabular}

use, for evaluating our results, the mean value $[-1364 \pm 99]$ as deduced by the Chronomodel calculations.

The prehistoric settlement of SKO is situated at the southwestern part of Thasos. This island, which belongs to the Rhodope zone, is composed by metamorphic rocks, mostly schists and gneisses, covered by coarse-grained marbles and dolomites. The upper horizons consist of sandstone with a marly matrix and clay intercalations, while alluvial deposits occur in the major bays. The settlement has been systematically excavated since the 1980s (KoukouliChrysanthaki 1989) and has been classified as Early-Middle Bronze Age. Traces of firing structures were unearthed indicating in situ production activities. Two habitation phases, referred as Skala Sotiros II and III from older to younger, have been defined for this site. The two phases are separated by a destruction level but no gap in the occupation of the settlement has been observed. In our previous study (Tema et al. 2012) we presented the archaeointensity results obtained from the study of six pottery fragments (SKS collection) corresponding to the latest habitation phase III, and which was initially dated between 2200 and $2100 \mathrm{yr}$ BC. Three new radio- carbon dates (DEM-1742, DEM-1743 and DEM 1852 in Table 1) allowed the chronological limits for SKS to be revised (KoukouliChrysanthaki et al. 2008; Koukouli-Chrysanthaki \& Papadopoulos 2016). Based on these three radiocarbon dates we have used the Chronomodel program to synthetize the results (Lanos \& Philippe $2015,2017)$. Since the radiocarbon samples correspond to different occupation moments of the SKS site, the Phase Time Range given by the program has been retained: [2221-1621 yr BC, 95 per cent level of confidence]. However, well-established recent archaeological constraints (see Koukouli-Chrysanthaki \& Papadopoulos 2016 for details) propose upper and lower limits for SKS at the end of the third millennium BC and the second century of the second millennium BC. Therefore an estimated time range between $2050 \mathrm{yr} \mathrm{BC}$ and $1800 \mathrm{yr} \mathrm{BC}$ is finally retained.

In the present contribution we focus on the archaeomagnetic study of 36 pottery fragments (here-and-after referred as the SKO collection, Fig. 1c) retrieved from the older habitation phase II of SKO, which is dated from the middle of the third millennium BC to its last century (Koukouli-Chrysanthaki \& Papadopoulos 2016). This phase is divided in three subphases $a, b$ and $c$ from older to younger. The fragments studied in the present study correspond to the older phases and were selected in order to put a clear chronological distance with phase III (SKS). Three radiocarbon dates, corresponding to the excavation plot from which our samples were retrieved, are given in Table 1 . The beginning of the SKO phase based on the Chronomodel synthesis of these three radiocarbon dates provides a mean age of [2750-2211 yr BC] (at 95 per cent level of confidence.) Moreover, we performed five luminescence analyses on the same fragments which were used for the archaeointensity experiment. The single-aliquot regenerativedose (SAR) protocol, introduced by Murray \& Wintle (2000), was used in order to estimate the equivalent dose by optically stimulated luminescence (OSL). All OSL measurements were performed 
Table 2. Summary of the new OSL experiments performed on the same pottery fragments studied for archaeointensity determination. The natural radioactivity data and the derived OSL dates are referred to year 2012 and not to 1950 as commonly used in radiocarbon dating.

\begin{tabular}{lcccccccc}
\hline A/A & $\begin{array}{c}\text { Lab } \\
\text { Code }\end{array}$ & $\begin{array}{c}\text { Ed } \\
(\mathrm{Gy})\end{array}$ & $\begin{array}{c}U \\
(\mathrm{ppm})\end{array}$ & $\begin{array}{c}\mathrm{Th} \\
(\mathrm{ppm})\end{array}$ & $\begin{array}{c}K \\
(\%)\end{array}$ & $\begin{array}{c}\text { DR } \\
\left(\mathrm{Gy} \mathrm{ka}^{-1}\right)\end{array}$ & $\begin{array}{c}\text { OSL dates referred } \\
\text { to year 2012 }\end{array}$ & $\begin{array}{c}\text { Calibrated Age BC } \\
(95 \% \text { level of confidence) }\end{array}$ \\
\hline 1 & SKO-23 & 15.955 & 4.167 & 7.551 & 1.73 & 3.5595 & $4305 \pm 225$ & {$[-2793,-1794]$} \\
2 & SKO-32 & 16.236 & 4.363 & 7.963 & 1.85 & 3.7716 & $4483 \pm 258$ & {$[-2977,-1966]$} \\
3 & SKO-33 & 14.925 & 3.852 & 8.512 & 1.56 & 3.3757 & $4421 \pm 221$ & {$[-2842,-1997]$} \\
4 & SKO-04 & 15.950 & 4.448 & 8.599 & 1.59 & 3.5891 & $4444 \pm 213$ & {$[-2850,-2015]$} \\
5 & SKO-12 & 15.560 & 4.012 & 8.112 & 1.69 & 3.5130 & $4429 \pm 212$ & {$[-2833,-2002]$} \\
\hline
\end{tabular}

at the Laboratory of Radiation Applications and Archaeological Dating, Athena-Research and Innovation Center in Xanthi, Greece. Further information of the protocol followed can be found in the Appendix. It is worth noting the remarkable internal consistency of the individual dating points associated to our studied fragments. The five OSL dating results are described in Table 2 and provide us a mean age for our collection of $2400 \pm 159 \mathrm{yr} \mathrm{BC}$. This mean age is very similar to the radiocarbon result when the mean value $[-2451 \pm 168]$ is selected. However, since the OSL results are directly obtained from the same fragments we used to derive the archaeointensity results, we decided to keep the mean OSL date as the final age for our collection.

The 47 pottery or baked clay fragments collected from both sites were treated at the Palaeomagnetic Laboratory of the Institute of Earth Sciences Jaume Almera ICTJA CSIC-CCiTUB (Barcelona, Spain). Four salt-pellet specimens were prepared per fragment following the same procedure used in our previous studies (Tema et al. 2012), taking into account that there is no control about the position of the specimens inside the salt-pellets. Specimens labelled A and B were used for pre-selection tests (magnetic mineralogy and thermal demagnetization analysis) while specimens $\mathrm{C}$ and $\mathrm{D}$ were used for the archaeointensity determination.

\section{EXPERIMENTAL PROCEDURES}

\subsection{Rock magnetism}

Archaeointensity determination from ancient potteries by means of the Thellier and Thellier method (Thellier \& Thellier 1959) is frequently characterized by a high failure rate, generally caused either by alteration of the magnetic minerals and consequently of their magnetic properties during laboratory heatings or by the presence of multidomain grains. Therefore, a good knowledge of the nature, the size and the thermal stability of the thermoremanence carriers present in the samples could be very useful for selecting the most promising ones for archaeointensity determination. For this reason we carried out several rock-magnetic tests before archaeointensity experiments.

At a first stage, stepwise thermal demagnetizations were performed on representative specimens using a Molspin magnetometer and a MMTD80 furnace at the Palaeomagnetic Laboratory of the Geophysics Department in the University of Thessaloniki. These experiments were performed in order to investigate the stability of the remanent magnetization of the samples and identify the specimens carrying two components of magnetization. Low-field monitoring of magnetic susceptibility versus temperature ( $K-T$ curves) was also performed for seven specimens. For the thermomagnetic analysis a Kappabridge KLY 3 (Institut de Physique du Globe, Paris) was used in order to determine the Curie point of the magnetic carriers, as well as their stability during heating. The experiments were carried out in air. Susceptibility values were recorded continuously from room temperature up to $630{ }^{\circ} \mathrm{C}$ and back to room temperature.

Thermal demagnetization of a three axes composite isothermal remanent magnetization (IRM; Lowrie 1990) was also carried out on three samples at the ALP Palaeomagnetic Laboratory (Peveragno, Italy). IRM was imparted with an ASC pulse magnetizer along three orthogonal axes with values of $0.1,0.5$ and $1.6 \mathrm{~T}$. Stepwise thermal demagnetization of the composite IRM was performed with a TSD2 Schonstedt furnace, following $40^{\circ} \mathrm{C}$ temperature steps. After each demagnetization step, the remanent magnetization was measured with a JR6 spinner magnetometer (AGICO). These experiments were performed in order to estimate the unblocking temperatures of the soft-, medium- and hard-magnetic components, respectively.

In addition, hysteresis curves and FORC diagrams were measured at the IPGP-IMPMC Mineral Magnetism Analytical Facility with a magnetometer ( $\mu$-VSM) from Princeton Measurements Corporation. These diagrams allow a qualitative characterization of the magnetic domain assemblage. They were performed at room temperature on selected samples. Hysteresis loops were measured between -0.5 and $0.5 \mathrm{~T}$ with an averaging time of $0.1 \mathrm{~s}$. FORC diagrams were measured with an averaging time of $100 \mathrm{~ms}$ and a saturating field of $1 \mathrm{~T}$. Depending on the sample, between one hundred and two hundred FORCs were used to calculate each FORC diagram. They were analysed with the VARIFORC software (Egli 2013), with a variable smoothing factor. The variable smoothing considerably reduces the noise levels by applying larger smoothing factors to the background, while preserving the areas along the axes with relatively small smoothing factors.

\subsection{Archaeointensity determination}

Archaeointensity determination was carried out at the Palaeomagnetic Laboratory of Géosciences-Rennes (Université de Rennes 1, France). The classical Thellier palaeointensity method (Thellier \& Thellier 1959) including regular partial thermoremanent magnetization (pTRM) checks and TRM anisotropy and cooling rate corrections upon archaeointensity estimates has been used. This method, based on the comparison between natural remanent magnetization (NRM) lost and partial thermoremanent magnetization (pTRM) gained in a known laboratory field, is one of the most accurate approaches for archaeointensity determination. Experiments were carried out in air. At each temperature step, the samples were first heated and cooled with a laboratory field of $50 \mu \mathrm{T}$ applied along their $Z$-axis and then, specimens were heated and cooled with the laboratory field applied in the opposite direction. The experimental procedures followed are the same as in previous studies (e.g. Gómez-Paccard et al. 2006, 2008, 2012b). In order to detect possible alteration in the magnetic mineralogy of the samples, regular partial thermoremanent magnetization (pTRM) checks were performed every two temperature steps. The TRM anisotropy and cooling rate effects upon intensity estimates were calculated at the 
specimen level. The TRM anisotropy tensor was determined from the acquisition of a TRM in six different directions applied during the Thellier experiment at temperatures at which around 70 per cent of the NRM intensity was lost. All NRM and TRM measurements were corrected for TRM anisotropy. In addition, the cooling rate dependence of TRM acquisition has also been estimated by applying four additional heating steps. A slow and free cooling time of about $24 \mathrm{hr}$ was used for the calculation of the cooling rate effect (see Gómez-Paccard et al. 2006 for further details of the protocol used to estimate the cooling rate correction factors). In order to guarantee the reliability of the intensity values, several quality criteria have been used to select acceptable Thellier experiments at the specimen level. First, pTRM checks have been considered as positive if, at a given temperature, the difference between the original pTRM and the pTRM check did not exceed 10 per cent of the total TRM acquired. Then, we fixed a limit of 50 per cent for the fraction of the initial NRM used for archaeointensity estimations (f parameter; Coe et al. 1978). Only linear NRM-TRM diagrams corresponding to well-defined straight lines going to the origin of the Zijderveld diagrams have been considered. The maximum angular deviation (MAD; Kirschvink 1980) and the deviation angle (DANG; Pick $\&$ Tauxe 1993) were restricted to $5^{\circ}$. The protocol applied provides, in our opinion, the bases to recover reliable archaeointensity estimations.

\subsection{X-ray powder diffraction analysis}

X-ray powder diffraction analysis provides a valuable tool to estimate the firing conditions of potteries by identifying the different mineral phases present in the composition of ceramic bodies. The presence or the absence of specific mineral assemblages can be used to determine the degree of thermal transformation undergone by the clay paste at the temperature and atmosphere applied during the firing procedure. Consequently, this information can be used to establish the firing conditions (temperature, atmosphere, time) achieved by potters during the operation of the kilns (Rathossi et al. 2010; Issi et al. 2011; Kramar et al. 2012; Matau et al. 2013; Ballirano et al. 2014; Compana et al. 2014; De Bonis et al. 2014; Holakooei et al. 2014). The results can reveal either the presence of primary minerals representative of their raw materials or the crystallization of new high-temperature minerals which are the product of reactions between the decomposed primary minerals as the temperature increases. The XRPD measurements were carried out with a Bruker D8 Advance Diffractometer with Ni-filtered Cu-Ka radiation, operating at $40 \mathrm{kV}, 40 \mathrm{~mA}$, and equipped with a Bruker LynxEye detector at the Department of Geology, University of Patras (Greece). The scanning area covered the interval $2-70^{\circ} 2 \theta$, with a scanning angle step of $0.015^{\circ}$ and a time step of $0.3 \mathrm{~s}$. Qualitative analysis of mineral phases was performed using the DIFFRACplus EVA software (Bruker-AXS, USA) based on the ICDD Powder Diffraction File. The minerals were quantified using a Rietveld-base quantification routine with the TOPAS software (DIFFRACplus TOPAS Ver. 3.0 Tutorial, Bruker-AXS, USA).

\section{RESULTS}

\subsection{Rock magnetic properties}

Before archaeointensity determination, a first selection of the material was done on the basis of the thermal demagnetization results followed by measurements of the low-field susceptibility after

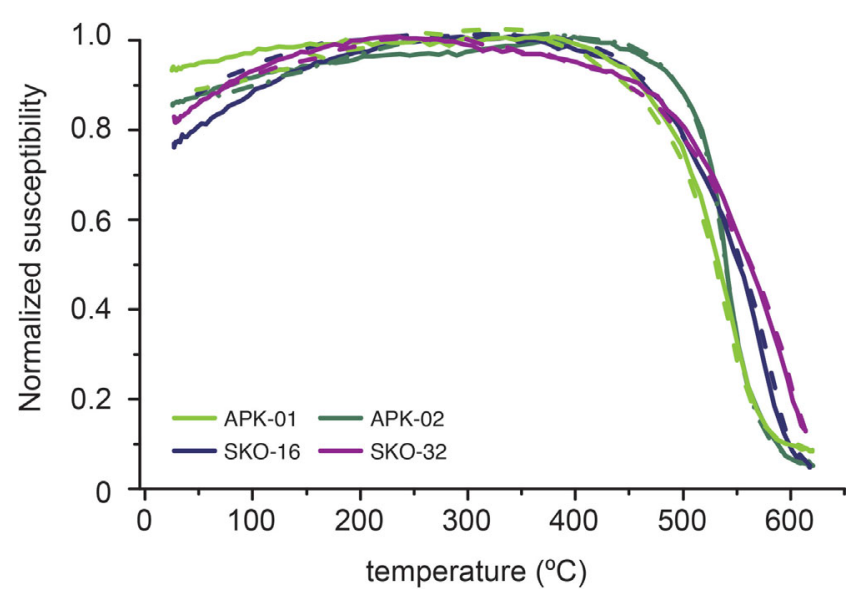

Figure 2. $K-T$ curves for four representative fragments. Continuous curves indicate the heating branches up to $630{ }^{\circ} \mathrm{C}$ and dotted curves the descending (cooling) branches.

each heating step. For the majority of the studied APK samples, a single magnetic component was identified after the removal of a viscous low-temperature component during the first temperature steps. On the contrary, some SKO samples showed a more complex behaviour, with two clear components of magnetization in the Zijderveld diagrams and were therefore rejected for archaeointensity experiments. After this initial pre-selection, the variations of the magnetic susceptibility with temperature were monitored. The provided thermomagnetic curves show a very good reversibility in most cases and exhibit a single slope change in both heating and cooling (Fig. 2). The corresponding Curie temperatures were calculated with the method of the second derivative and vary between 550 and $580^{\circ} \mathrm{C}$ for the APK samples, resulting from the dominance of magnetite or Ti-poor titanomagnetite. On the contrary, higher Curie temperatures from 595 to $620{ }^{\circ} \mathrm{C}$ are observed for the four SKO samples, suggesting the presence of thermally stable maghemite in these samples. Stable maghemite has been observed in previous archaeomagnetic studies (Catanzariti et al. 2012).

Thermal demagnetization of three-axis IRM experiments (Lowrie 1990) for APK-10A and SKO20-B are plotted in Figs 3(a) and (b), respectively. The other analysed specimen (SKO-31A) shows a very similar behaviour to SKO-20B. In agreement with the thermomagnetic curves, these experiments indicate the progressive and nearly complete demagnetization of the IRM below $590{ }^{\circ} \mathrm{C}$. They also reveal that most of the magnetization is carried by the magnetically soft fraction $(<0.1 \mathrm{~T}$, blue dots in Fig. 3) while the medium and high-coercivity components are generally minor (green and red dots). This is consistent with the dominance of a low coercivity mineral, most probably magnetite, Ti poor-magnetite or maghemite.

Hysteresis properties were measured for five specimens from the APK site and nine from the SKO site. The Day plot (Day et al. 1977) in Fig. 4 gives a general overview of the parameters obtained from the hysteresis curves. As generally observed in archaeological materials, the values of $H_{\mathrm{cr}} / H_{\mathrm{c}}$ and $M_{\mathrm{rs}} / M_{\mathrm{s}}$ fall in the pseudo-single domain range. This indicates the presence of a mixture of single domain (SD) and multidomain (MD) or SD and superparamagnetic (SP) grains in the studied samples. In order to further investigate the grain size of the studied material, FORC diagrams were performed. The FORC diagrams for three out of the four studied samples from APK site show two peaks: one very close to the origin, with almost vertical contours, characteristic of SP grains, and one centred at a coercivity around $10-15 \mathrm{mT}$, with contours extending up to $60 \mathrm{mT}$, 

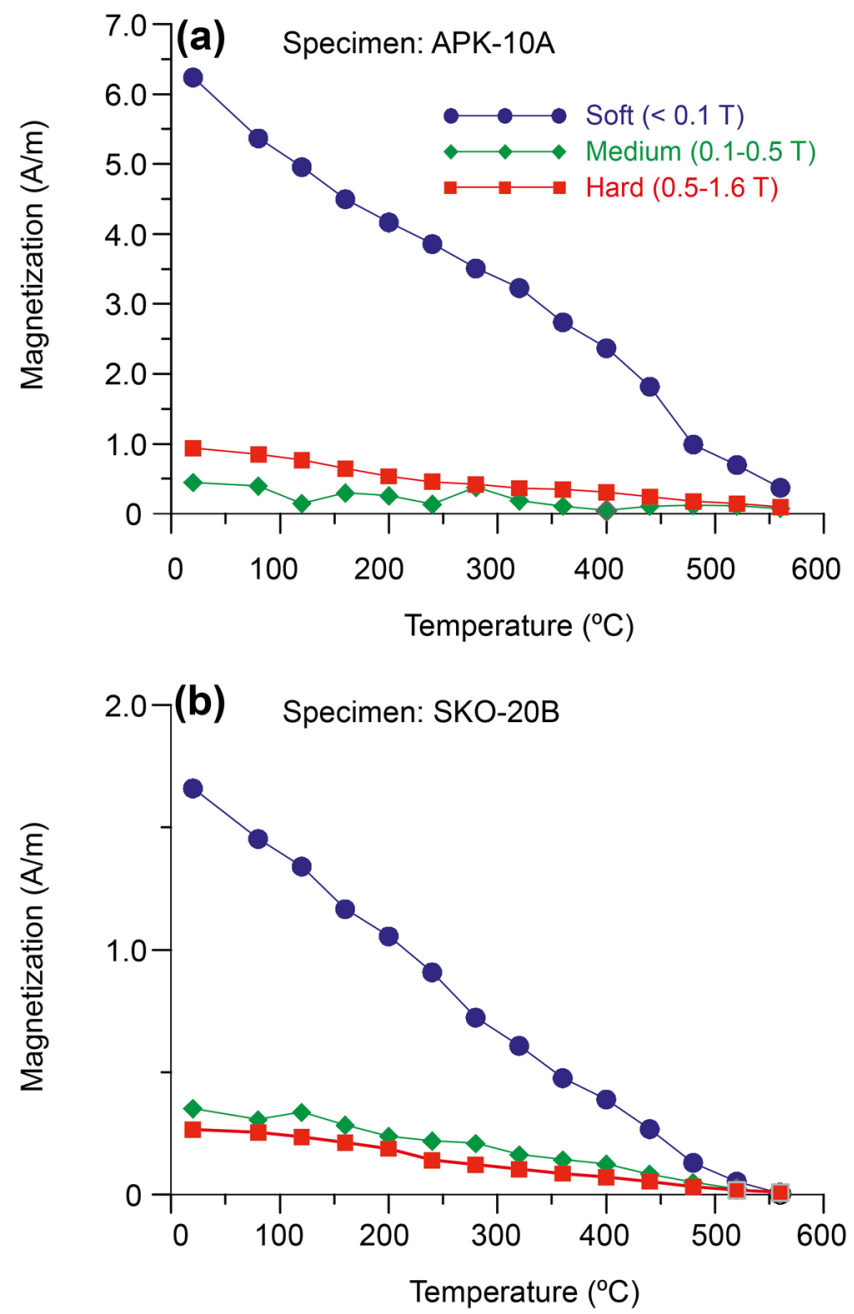

Figure 3. Thermal demagnetization of orthogonal three-axis composite IRM for two representative fragments from APK-up and SKO-down.

characteristic of stable SD grains (Roberts et al. 2000; Fig. 5a). The spread along the horizontal axis is limited (full width at half maximum (FWHM) of the FORC profile along the vertical passing through the peak $<10 \mathrm{mT}$ ), indicating that magnetostatic interactions are not important. The FORC diagrams for samples APK-3 and APK-6 show only one SP peak that extends along the horizontal axis. The 11 studied samples from SKO site are also characteristic of an assemblage of SP and SD grains in various proportions (Figs $5 \mathrm{~b}$ and c), with maximum coercivities as high as $100 \mathrm{mT}$. The FWHM of the SD peak along the vertical axis is also smaller than $10 \mathrm{mT}$. According to the FORC diagrams, the carriers of the magnetization in the samples from both sites are very fine grains with moderate interactions and at a first approach they should be favourable for Thellier-Thellier archaeointensity determinations.

\subsection{New archaeointensity data from the Greek Bronze Age}

On the basis of the rock-magnetic experiments described in the previous section, the most promising fragments were selected for archaeointensity determination. A total of 10 ceramic fragments from APK and 13 fragments from SKO (in both cases two specimens per fragment) were analysed following the Thellier and Thellier protocol described in the previous section. Two types of behaviour have been observed: some specimens showed a well-defined straight line

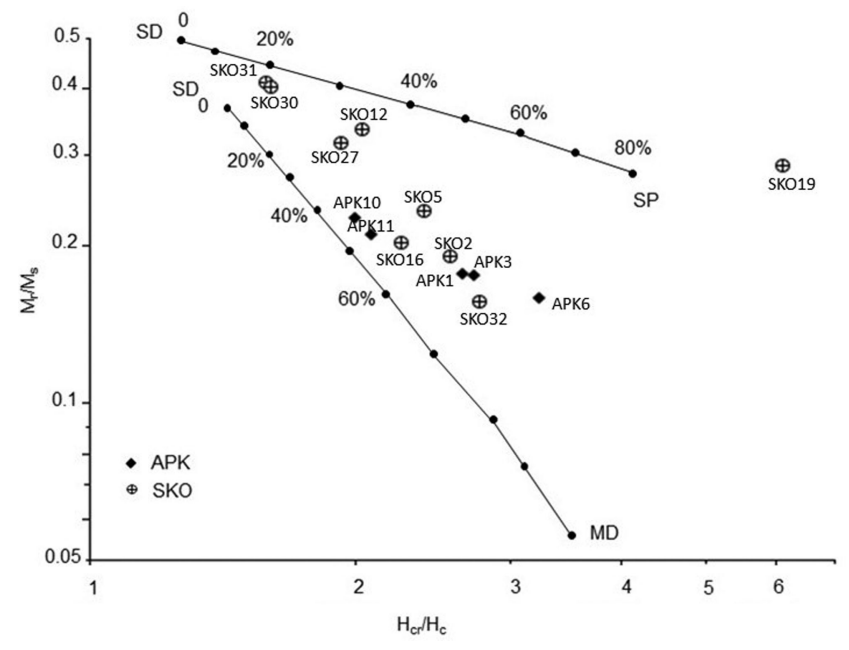

Figure 4. Hysteresis parameters for the APK and SKO samples. The SD$\mathrm{MD}$ and SD-SP mixing lines are calculations for magnetite from Dunlop (2002).

going towards the origin of the Zijderveld plots after removal of a weak secondary component of magnetisation (Figs 6a-d). This characteristic component likely corresponds to the TRM acquired during the manufacture of the fragments. The maximum unblocking temperatures observed range between 470 and $580{ }^{\circ} \mathrm{C}$, which is in agreement with the rock-magnetic results described previously. For these specimens linear NRM-TRM diagrams are obtained. However, some specimens show a more complex behaviour with straight lines not pointing to the origin of the Zijderveld plots, with nonlinear NRM-TRM plots (Fig. 6e) or showing a clear failure of the pTRM checks even if very well-defined straight lines going towards the origin are observed in the Zijderveld diagrams (Fig. 6f). These features very likely correspond to mineralogical changes and, according to the selection protocol described before, these samples were discarded for archaeointensity calculations. Twenty archaeointensity determinations (13 from APK and 7 from SKO, see Supporting Information Table S1) were accepted. The accepted archaeointensities correspond to 7 and 4 independent fragments from APK and SKO, respectively ( $\mathrm{N}$ in Table 3). The NRM fraction used for archaeointensity determination ranges between 0.52 and 0.79 corresponding to quality factors between 4.2 and 41.5 (see Supporting Information Table S1). The effect of TRM anisotropy upon archaeointensity determination has been investigated for all specimens. Differences between the uncorrected and TRM anisotropy corrected values lower than 10 per cent are observed except for APK-03D for which a value of 10.5 per cent has been obtained. The cooling rate calculated factors are lower than 10 per cent. In some cases the alteration which occurred during the cooling rate protocol (see Supporting Information Table S1) hampered a reliable estimation of this effect and the uncorrected values were used to derive mean intensity results.

From the 20 archaeointensities obtained at the specimen level we calculated first, a mean per sample when more than one specimen were available, and then a mean intensity value for each site. The means were derived using the mean weighting factors as suggested by Prevot et al. (1985). The two new mean intensities are summarized in Table 3. They have been obtained from 7 (APK) and 4 (SKO) independent fragments and from 13 and 7 specimens, respectively. Mean values of $67.4 \pm 5.4 \mu \mathrm{T}$ for the APK site and of $76.9 \pm 6.0 \mu \mathrm{T}$ for SKO are retained. The protocol and the number of specimens used to derive these means correspond to the A 'high-quality' category defined in Pavón-Carrasco et al. (2014a). 

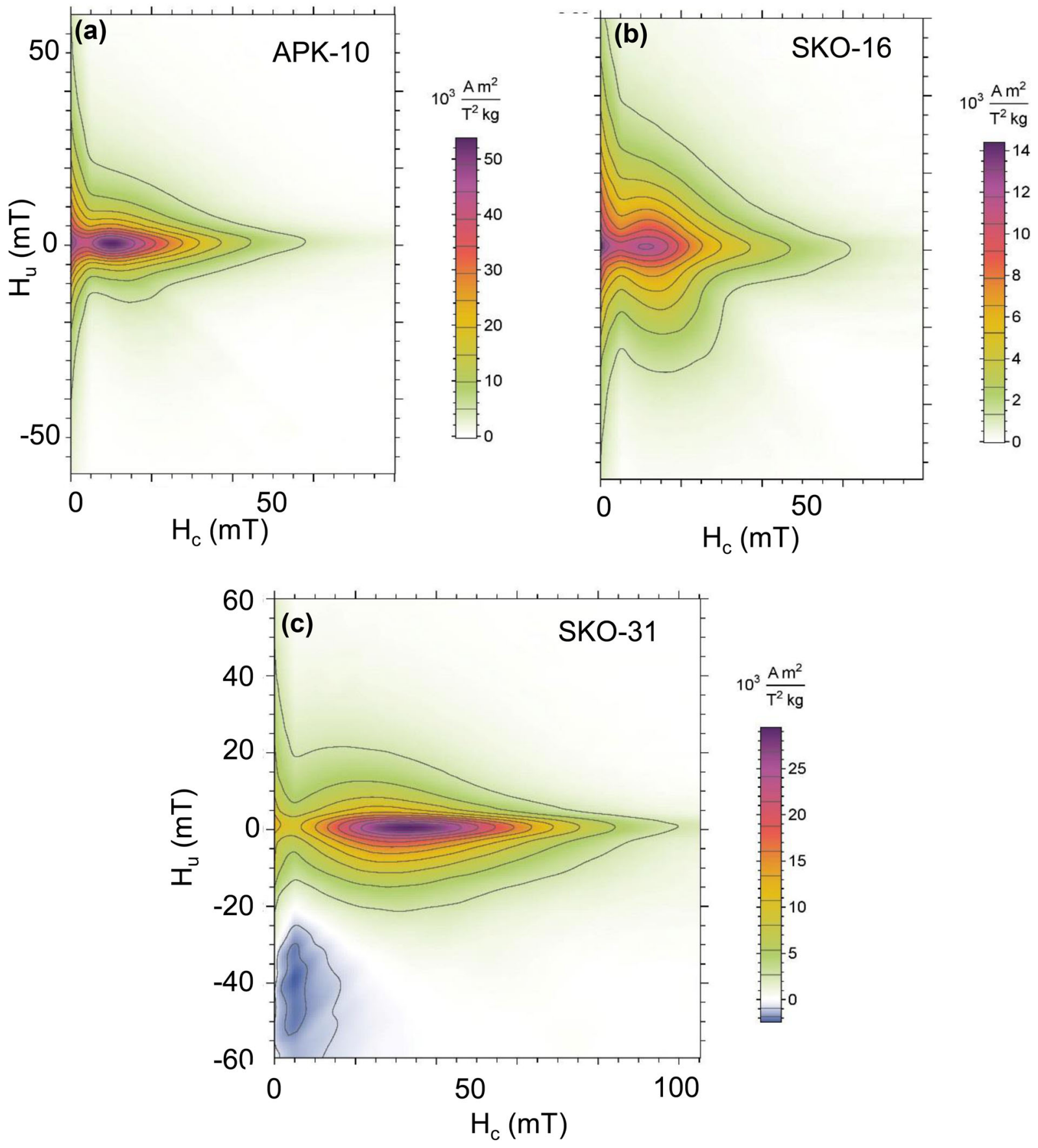

Figure 5. FORC diagrams for samples APK-10 (a), SKO-16 (b) and SKO-31 (c). 200 FORCs measured with an averaging time of 100 ms were processed with the VARIFORC software of Egli (2013). Note that the $H_{\mathrm{c}}$ and $H_{\mathrm{u}}$ scales are the same on the two diagrams.

Approximately 40 per cent for the APK, and 73 per cent of the SKO specimens studied were rejected for the archaeointensity determination. These results suggest that the classical pre-selection criteria applied here (one single component of magnetization, reversibility of thermomagnetic curves and fine grains with moderate interactions) do not guarantee reliable archaeointensity estimations.

\subsection{Re-evaluation of previous results through magnetic measurements}

The number of reliable archaeointensity data in Europe is constantly increasing but the success rate of the Thellier method and its variants remains low, hampering the satisfactory coverage of areas or archaeological periods. In the literature, several pre-selection procedures before archaeointensity determinations have been proposed (e.g. Cui \& Verosub 1995; Cui et al. 1997; Jordanova et al. 1997, 2001; Leonhardt et al. 2004; Carvallo et al. 2006). Nevertheless, some of these procedures are almost as time consuming as a Thellier experiment and a full success cannot still be guaranteed. For example, our first attempt to obtain archaeomagnetic data from Prehistoric Greek ceramics had also a moderate success (Tema et al. 2012) and this was followed by a total failure (Fanjat et al. 2013), while in both studies standard magnetic mineralogy experiments and material selection criteria were applied. It is therefore 

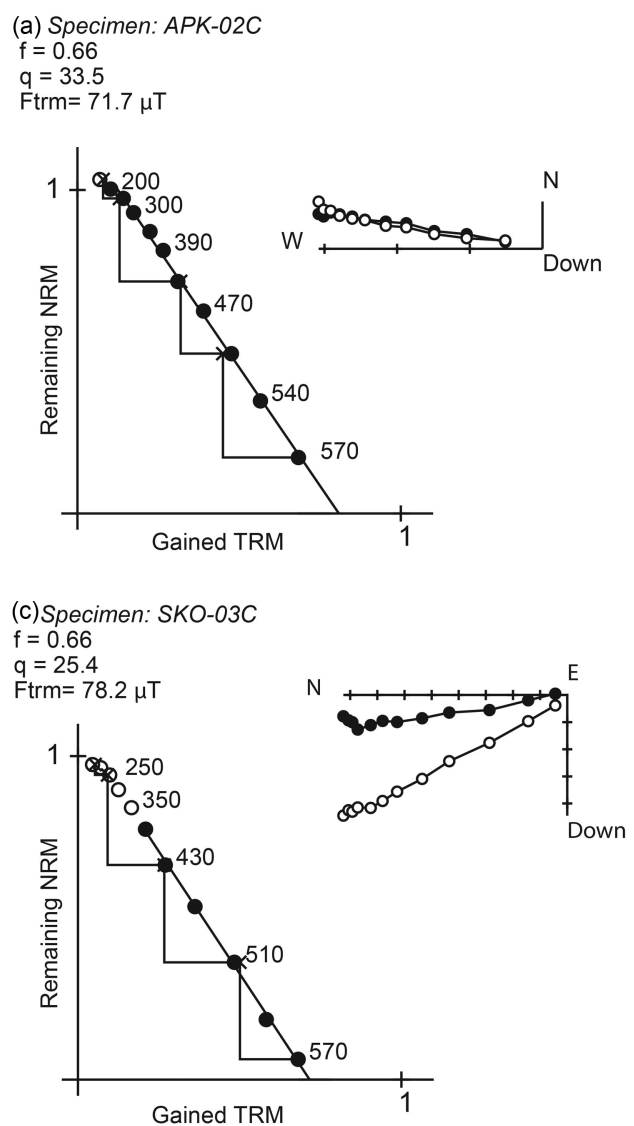
(e) Specimen: APK-09C
Rejected

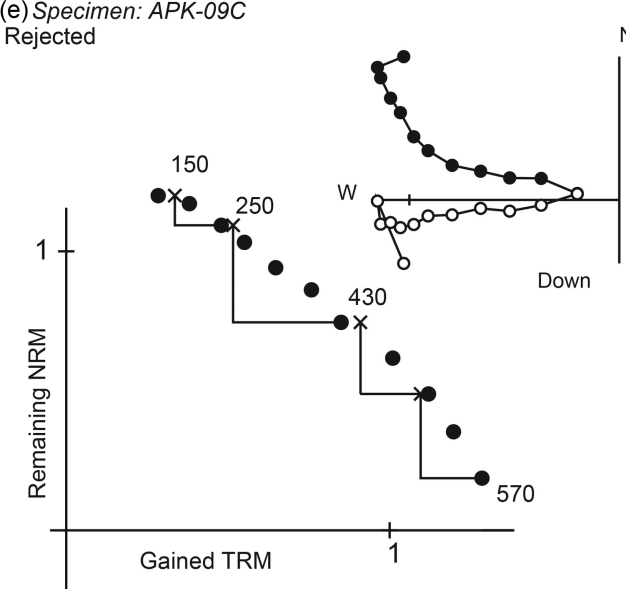

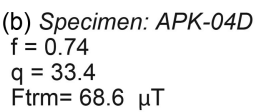

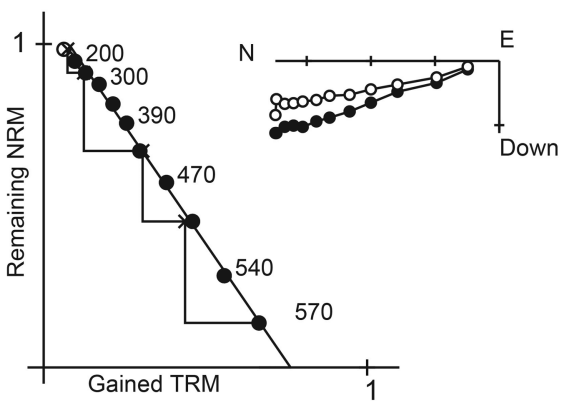

(d) Specimen: SKO-16C

$f=0.71$

$q=36.1$

Ftrm= $73.0 \mu \mathrm{T}$
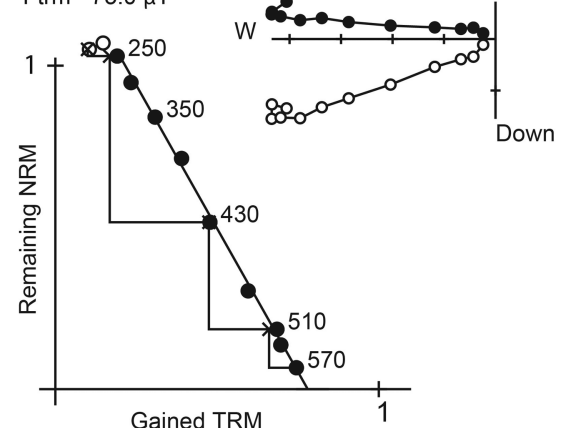

(f) Specimen: SKO-31C Rejected

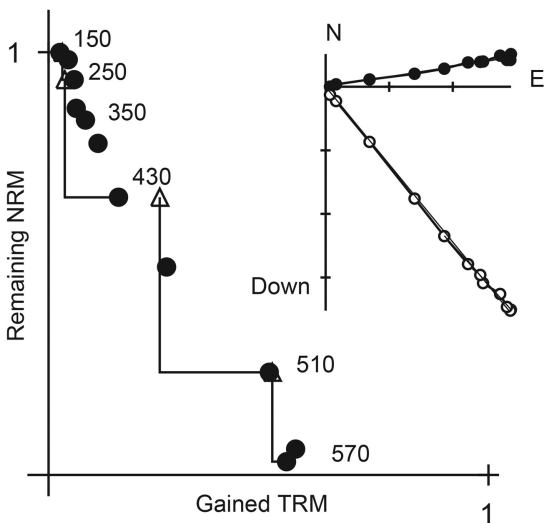

Figure 6. Typical NRM-TRM diagrams. Examples of accepted (a-d) and rejected (e, f) archaeointensity results of representative specimens. The NRM-TRM diagrams are shown together with the Zijderveld diagrams, in sample coordinates. In the Zijderveld diagrams, open (solid) circles are projections upon vertical (horizontal) planes. NRM-TRM plots are normalized to the initial NRM intensity and for the accepted data (a-d) closed circles correspond to temperature steps used for archaeointensity determinations. The estimated archaeointensity after TRM anisotropy correction (Ftrm), the NRM fraction used and the corresponding quality factor $(q)$ are indicated.

necessary to further investigate the possible causes of this failure and explore alternative approaches for pre-selection criteria.

In this perspective we decided, first, to re-examine the magnetic properties of previously studied Greek prehistoric ceramics. A considerable number of prehistoric intensity data from Greek ceramics and pottery collections are available. Nevertheless several problems have been outlined for this data set, mainly related to the laboratory protocols applied and to the lack of standard quality criteria as, for example, pTRM checks (for a review see De Marco et al. 2008). For this reason, in the present study we revise only data obtained according to the most recently adopted protocols and with direct involvement of one or more researchers from our group.

Apart from the two sites presented here, four Greek pottery collections have been analysed within the above frame: ARH and SKS (Tema et al. 2012) and Dikili-Tash (DTc) and Vassili (BSc; Fanjat et al. 2013). The mean intensities derived from these previous studies are also reported in Table 3, together with our new results. A brief overview is provided as Supporting Information M1 (further details can be found in the corresponding publications). In an effort to obtain additional information about the magnetic mineralogy of 


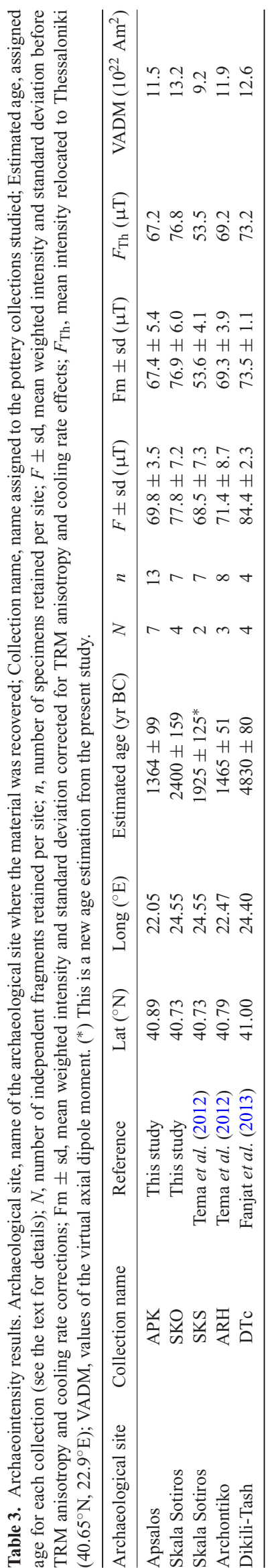

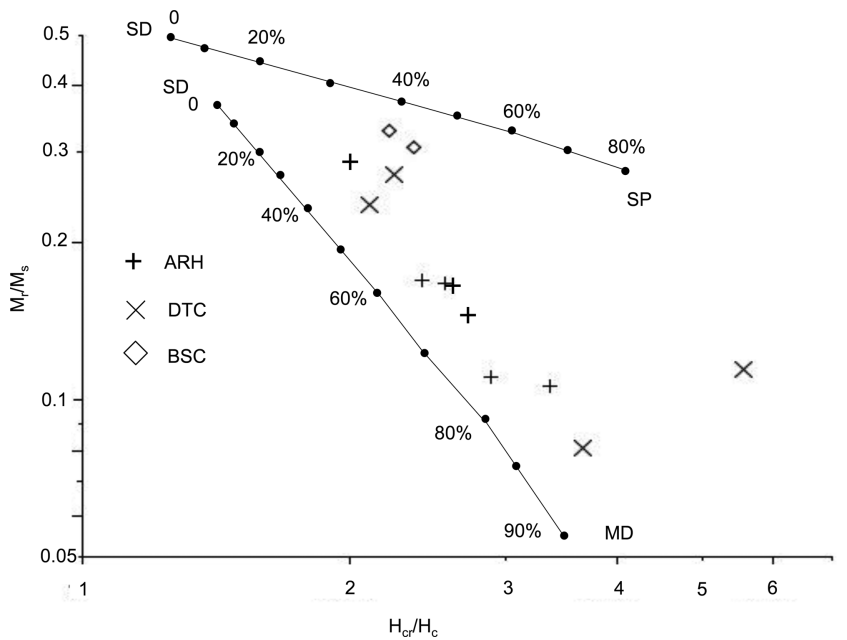

Figure 7. Day plot (Day et al. 1977) of ARH, DTc and BSc specimens. The SD-MD and SD-SP mixing lines are calculations for magnetite from Dunlop (2002). Numbers along curves are volume fractions of the soft component (SP or MD) in mixtures with SD grains. All the data plot on the PSD range.

these collections and investigate if the cause of the archaeointensity failure was the presence of $\mathrm{MD}$ grains, we performed additional hysteresis and FORC experiments not included in these studies. Fortunately, in all but one case (site SKS) a sufficient quantity of non-treated material was still available. We consider this gap as insignificant since sites SKS and SKO belong to the same settlement but to different habitation levels. Thus, the raw materials used for the pottery remain the same as attested also by relevant chemical analyses (Kilikoglou \& Tsolakidou 2012).

Hysteresis parameters fall between the SD-SP and SD-MD mixing lines (Fig. 7). The four FORC diagrams of samples from the Arhontiko (ARH) site are all very similar to the FORC diagrams of the new APK and SKO sites and also show the presence of a mixture of non-interacting SP and SD magnetic grains (see two examples in Figs $8 \mathrm{a}$ and $\mathrm{b}$ ). Sample ARH-5 has contours that are more spread along both axes than the other three samples (Fig. 8b). The four samples from Dikili-Tash (DTc) also show FORC diagrams that are characteristic of an SD-SP mixture with little interactions. The SD peak of the distribution is between 10 and $30 \mathrm{mT}$, so the two peaks are more or less well separated (Fig. 8c). Finally, the two analysed samples from Vassili (BSc) are characterized by a SP peak close to the origin and a well-separated SD peak with contours extending up to over $100 \mathrm{mT}$ (Fig. 8d), with little spread along the horizontal axis. From these analyses, it appears that FORC diagrams of all examined samples suggest that they are suitable for successful Thellier-type experiments. However, and as pointed out before, this was not the case for most of the studied sites. In order to enrich our magnetic data set, we decided to perform a series of hysteresis experiments from different layers within the ceramics. The measurements were carried out at room temperature with a P.A.R.155 Vibrating Sample Magnetometer (VSM) in the Physics Department, University of Thessaloniki. We performed the experiments on 14 samples of the same collection, selected on the basis of their success or failure during the Thellier experiment. Each fragment was cut with a diamond wheel in three layers of $5 \mathrm{~mm}$ thick each. A first specimen was prepared from the outer layer of the fragment's surface ( $t$ : top); two more specimens were cut from the middle and inner part layers ( $\mathrm{m}$ : middle, b: bottom). The specimens corresponding to the three different layers were pulverized and the produced powder was 

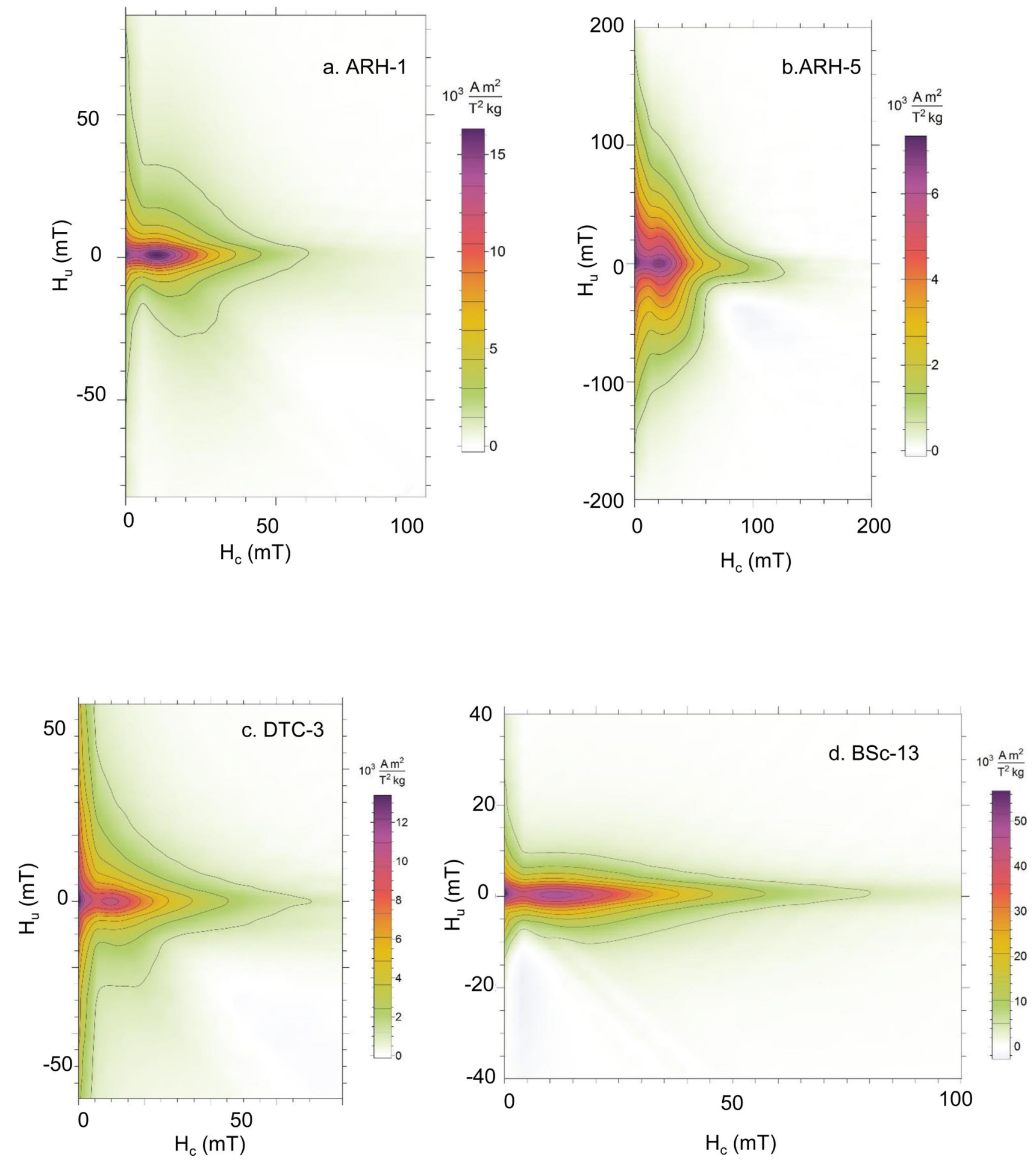

Figure 8. (a-d) Representative FORC diagrams for the ARH, DTc and BSc specimens. A total of 200 measured FORCs with an averaging time of 100 ms were processed with the VARIFORC software of Egli (2013). Note that the $H_{\mathrm{c}}$ and $H_{\mathrm{u}}$ scales are the same on the different diagrams.

homogenized. A sample powder of $50 \mathrm{mg}$ from each layer was used to trace the magnetization hysteresis loop. This procedure allows to check the magnetic homogeneity of the examined samples. Among the 14 samples examined, 7 are fairly homogeneous and 7 display a clear inhomogeneity with the main feature being the magnetically different surface layer due either to varnishing which was not de- tected visually or to the firing procedure. Some examples are given below:

(1) Within the thickness of $15 \mathrm{~mm}$ (that is approximately the mean thickness of the ceramic fragment used for archaeomagnetic studies), differences either on the magnetic phases or amounts 
of similar magnetic minerals appear with a clear differentiation on the material's magnetic phase from the external layer (Fig. 9a).

(2) Within the same thickness of $15 \mathrm{~mm}$, one magnetic phase could be present, with the concentration of SD magnetite diminishing with depth (Fig. 9b).

(3) In another case the SD magnetite content is increasing with depth (Fig. 9c).

(4) The remaining eleven curves and relevant comments can be found in Supporting Information Figs S1-S11.

\subsection{Detailed mineralogical description and inferred firing conditions}

As a final step, 22 sherds from APK, ARH, SKO, and SKS have been subjected to detailed mineralogical examination by means of XRPD analysis. Additionally, we compiled and extended the corresponding published XRPD data from BSC and DTc sites (Fanjat et al. 2013) for a better comparison. The results were used to assess the firing conditions (temperature, atmosphere, duration) and the proportion of Fe-bearing minerals (hematite, magnetite). The deduced mineralogical composition of each analysed ceramic fragment is a good recorder of the degree of pyrometamorphism, which occurred during the firing procedure and, as a consequence, of the firing conditions that prevailed in the combustion place, either kiln or open fire. Moreover, the coexistence of specific minerals (e.g. Ca-Al silicates minerals or Al-silicate minerals, oxides) in mineralogical assemblage, could offer information for the chemical composition of the clay materials used for the ceramic production. Fig. 10 and Table 4 present the main results obtained, including the weight percentages of Fe-bearing minerals, the estimation of firing conditions, and the macroscopic observation of the ceramic body colour. We report here the main conclusions derived for the different studied sites from north to south:

\subsubsection{APK ceramic collection}

The selected clay paste for the production of APK pottery was mainly Ca-poor and Fe-rich suggested by the red colour of sherds and the absence of carbonate minerals in most samples (only two samples include dolomite in their mineral composition, probably made by different clay mixture). The mineralogical results from APK pottery are compatible with relatively low firing temperatures $T \approx 500$ to $750^{\circ} \mathrm{C}$. This conclusion is derived from the fact that many primitive minerals, such as chlorite and dehydrated smectite that define the very low firing $T \approx 500-650^{\circ} \mathrm{C}$ as well as talc and actinolite which indicate a slightly higher temperature (up to $750^{\circ} \mathrm{C}$ ), are still preserved and no evidence for neocrystallization, as a result of high firing process, has been detected (Mackenzie 1957; Grim 1968; De Souza Santos \& Yada 1988; Moore \& Reynolds 1989; Kloprogge \& Frost 2000; Grapes 2006; Rathossi et al. 2010; Table 4). Hematite is the dominant Fe-bearing mineral, which was quantified in five out of six samples (Fig. 10 and Table 4), indicating the prevailing oxidizing or mildly oxidizing atmosphere (lower magnetite content) during their firing.

\subsubsection{Arhontiko (ARH) ceramic collection}

The geological background of the archaeological site consists of neogene sediments (marls, red clay, sand) which are in contact with an ophiolitic complex, composed of plutonic and volcanic rocks,
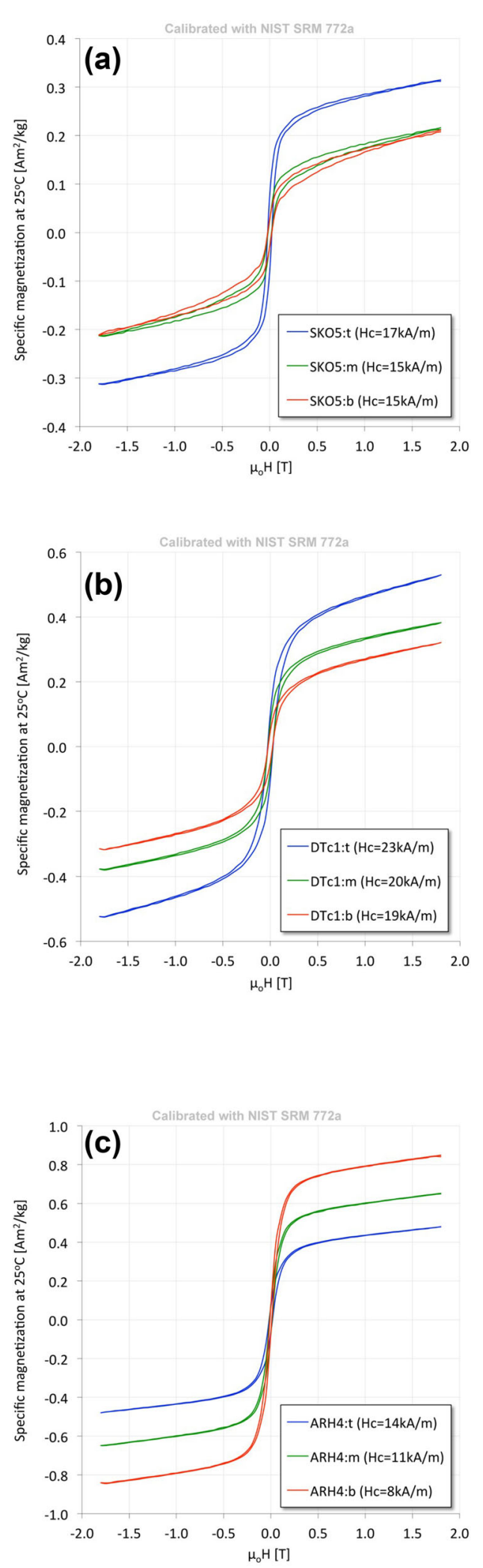

Figure 9. Layered magnetization measurements for three representative samples. The magnetic inhomogeneity is clearly shown (see the text for details). 

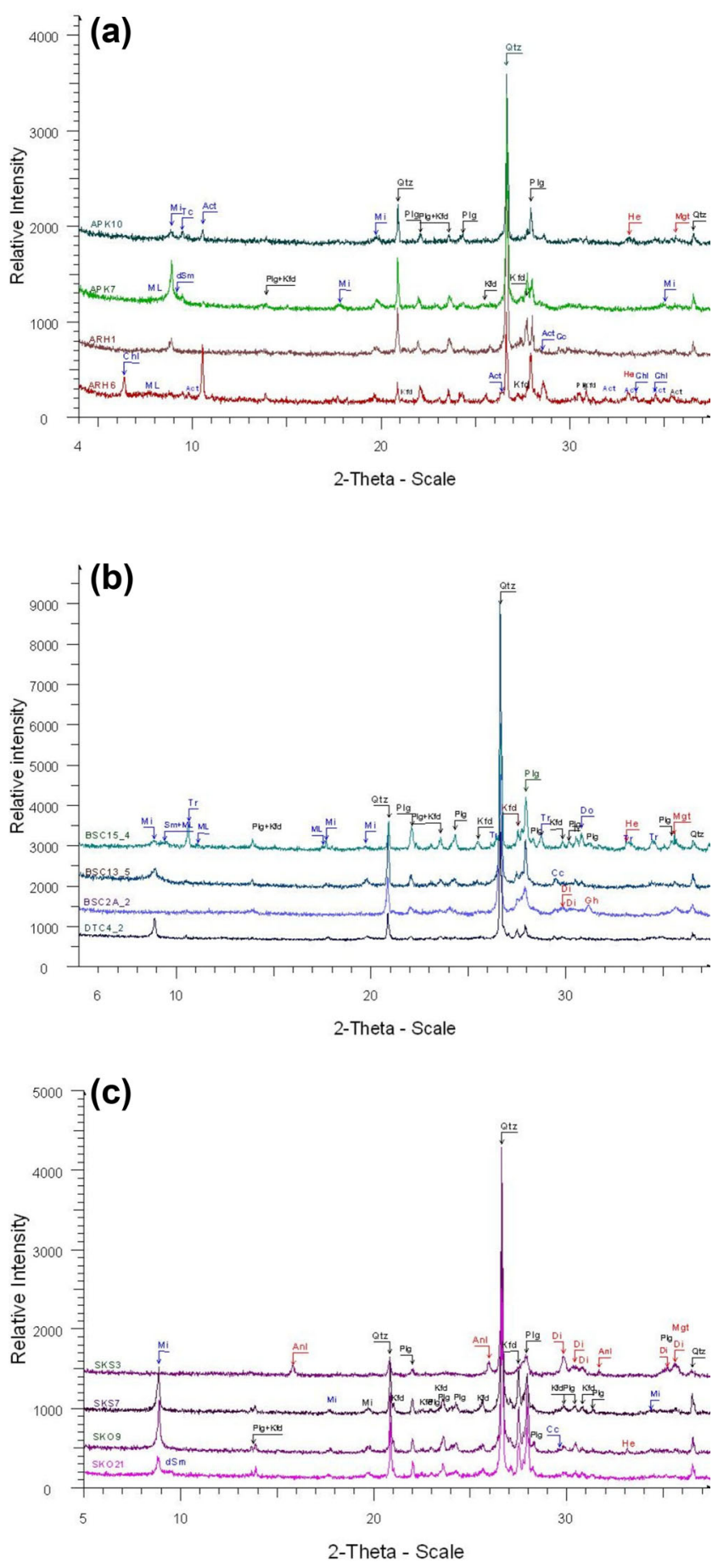

Figure 10. X-ray diffraction patterns of representative samples at various firing temperatures from the five studied sites, that is, (a) APK/ARH, (b) BSc/DTc (Fanjat et al. 2013) and (c) Skala-Sotiros (SKS, SKO). The estimated firing temperature for each sample is given in Table 4. Abbreviations: Qtz, quartz; Plg, plagioclase; Kfd, k-feldspar; Cc, calcite; Do, dolomite; Mi, white mica; Chl, chlorite; Sm, smectite; dSm, dehydrated smectite; Tc, talc; Act, actinolite; Tr, tremolite; Di, diopside; Anl, secondary analcime; He, hematite; Mgt, magnetite.

as well as with metamorphic rocks (marbles, schists). According to archaeological information, the ceramics from the late Bronze Age period were characterized as coarse to fine grain wares with inclusions of quartz, calcite, mica and traces of organic materials. They were probably fired at temperatures between 750 to $900 / 950{ }^{\circ} \mathrm{C}$ in oxidizing conditions (Deliopoulos 2014). The samples analysed in this study, present rock fragment inclusions in their composition with a grain-size up to $5 \mathrm{~mm}$. Their firing conditions, as recorded by the mineralogical analysis of ceramic body, indicate that in samples ARH4, ARH5, ARH6 the detected reflections of primary clay minerals which were components of the clay paste, such as dehydrated chlorite (at $\approx 13.85 \AA$ ) and dehydrated smectite mark a low firing $T \approx 550-600{ }^{\circ} \mathrm{C}$ (Mackenzie 1957; Grim 1968; Moore \& Reynolds 1989; Rathossi et al. 2010). On the contrary, the absence of clay minerals in samples ARH1, ARH3, ARH7, ARH9 and the trace of undecomposed calcite ( $<2.0 \mathrm{wt}$ per cent), without any trace of neocrystallization, suggest $T \approx 750-800{ }^{\circ} \mathrm{C}$ (Shoval et al. 1993; Murad \& Wagner 1998; Rathossi \& Pontikes 2010a; Fig. 10c, Table 4). The percentage content of magnetic minerals is low, circa 1 to 2 wt per cent for the majority of the samples (six out of seven; Table 4). The mineralogical assemblages point out to two kinds of clay paste used for the ceramic production, a Ca-poor which refers to three of the analysed samples and a Ca-rich clay for the other four samples (trace of calcite). This discrimination suggests a different raw material source.

\subsubsection{Dikili-Tash (DTc) ceramic collection}

The site is located in a geological setting consisting of metamorphic rocks such as marbles, gneisses and mica schists and smaller outcrops of recent terrestrial sediments. The mineralogical composition of the analysed samples reveals that the firing temperature was sufficient for the decarbonation of calcite $\left(750-800{ }^{\circ} \mathrm{C}\right)$, derived by marble grains. Nevertheless, only in one sample, DTc1_4, the firing temperature exceeded $800{ }^{\circ} \mathrm{C}$ and led to the crystallization of new high $\mathrm{T}$ phases (e.g. gehlenite and ferrian aluminian diopside (fassaite)) but did not transcend $900{ }^{\circ} \mathrm{C}$ since the white mica structure persists (Rathossi \& Pontikes 2010a; Fanjat et al. 2013; Fig. 10a, Table 4). The high temperature mineral phases in sample DTC1_4 indicate that its clay paste could be characterized as CaFe-rich clay coming from the surrounding area. In a thorough study of the geological environment around Dikili-Tash through petrographic and pedological examination, Germain-Vallée et al. (2011) have localized the sediments contemporary to the site's functioning. This lead to the conclusion that a fine-texture soil was used for the construction of fired material in the site. It is very likely that the same material was included in the production of ceramics. The amount of magnetite Fe-oxides is relatively low, up to 1.55 wt per cent probably due to the incorporation of the iron ions in the structure of high $T$ mineral phases (Table 4; Rathossi \& Pontikes 2010b and references therein, Rathossi et al. 2010).

\subsubsection{Skala Sotiros (SKO and SKS) ceramic collections}

The settlement is situated on recent deposits (clay, sand, gravel) and metamorphic rocks (marbles, mica schists, amphibolites gneisses). Several petrographic and chemical analyses were performed in the past on Thasian clays (Kilikoglou \& Tsolakidou 2012; Youni 2012) and the ones directly related to this site will be further discussed in the last paragraph.

Our mineralogical examination on nine samples indicated that the firing temperature, for most studied samples (SKO5, SKO9, SKO16, SKS1, SKS2, SKS7) ranges between 700 and $800{ }^{\circ} \mathrm{C}$, as suggested by the preservation of calcite even in low amounts (up to $3 \mathrm{wt}$ per cent) or its absence in combination with the absent 


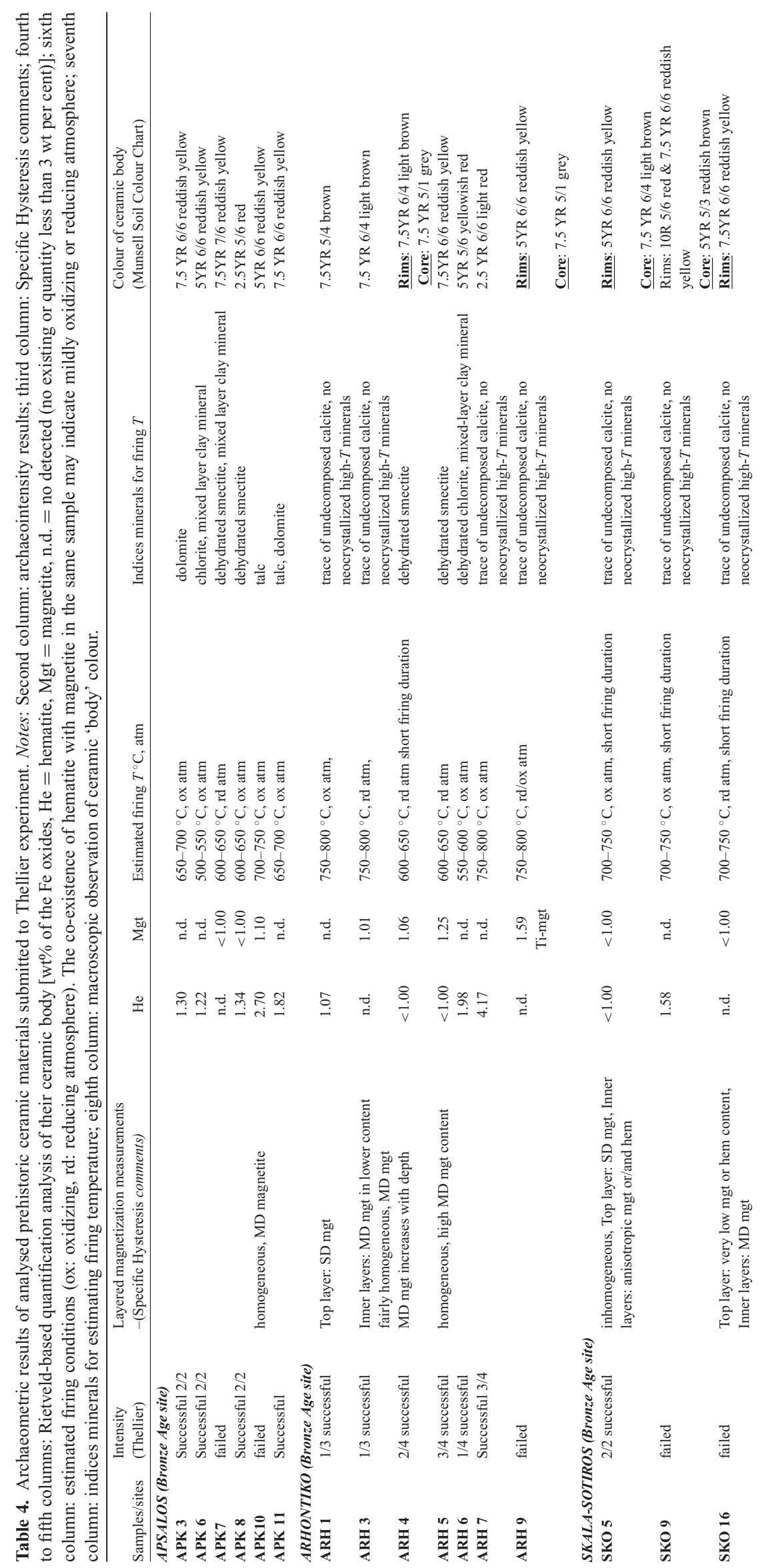




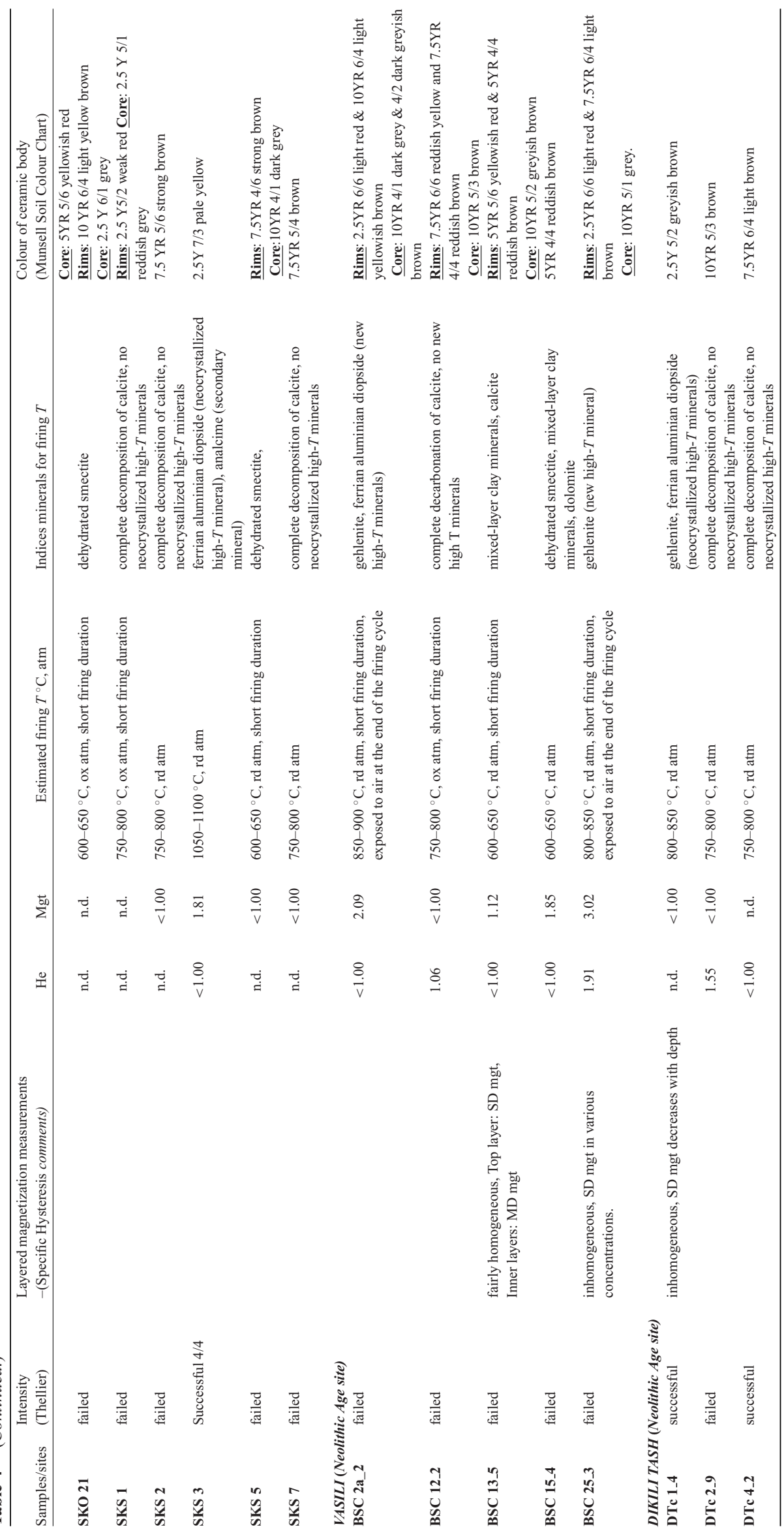


neoformed calcium aluminium silicate minerals (i.e. diopside, gehlenite, anorthite; Shoval et al. 1993; Murad \& Wagner 1998; Moroni \& Conti 2006). Only two samples (SKO21 and SKS5) exhibit low firing $T \approx 600-650{ }^{\circ} \mathrm{C}$ according to the presence of the dehydrated clay mineral smectite (peak at $d \approx 9.60 \AA$; Mackenzie 1957; Grim 1968; Moore \& Reynolds 1989). Sample SKS3 has been fired at extremely high temperature $T \approx 1050-1100{ }^{\circ} \mathrm{C}$ assessed by the high amount of neocrystallized ferrian-aluminiandiopside (fassaite) $\mathrm{Ca}\left(\mathrm{Fe}^{3+} \mathrm{Mg}\right) \mathrm{AlSiO}_{6}(\approx 35 \mathrm{wt}$ per cent) and the high concentration of analcime $(\approx 9.0$ wt per cent; Rathossi \& Pontikes 2010a; Fig. 10b, Table 4). The last is a secondary mineral formed by the post-depositional alteration of ceramic's glassy phase (Schwedt, et al. 2006). Concerning the iron oxide content, a very low amount has been calculated, and only two samples contain hematite 1.58 wt per cent (SKO9) and magnetite 1.81 wt per cent (SKS3; Table 4). The sample SKS3 suggests that its clay paste for the ceramic production in Skala Sotiros could have been derived from Ca-Fe-rich sediments.

\subsubsection{Vassili (BSc) ceramic collection}

A wide range of firing temperatures from 600 (two samples) up to $900^{\circ} \mathrm{C}$ (three samples) has been determined for the pottery of Vassili as deduced by the presence or absence of calcium-aluminium silicate minerals. Magnetic iron oxides, hematite or magnetite or both, have been found to be developed in all samples (Table 4). More details can be found in Fanjat et al. (2013).

\section{DISCUSSION}

5.1 Comparison with previous Greek archaeointensity data and geomagnetic field models results corresponding to the prehistoric period (from the seventh to the beginning of the first millennium $\mathrm{BC}$ )

The new high-quality archaeointensities proposed here for Greece can now be compared to the Greek archaeointensity database as well as with the results derived from different geomagnetic field models. The first consistent archaeointensity data set for prehistoric Greece was presented by Thomas (1981), together with several thermoluminescence (TL) and radiocarbon datings, in a Thesis carried out at the University of Edinburgh. In a subsequent publication, the author presented only an outline of her basic results (Thomas 1983). Tema \& Kondopoulou (2011) compiled the original data of Thomas (1981) and noted systematically lower values for the Neolithic and Chalcolithic periods, (broadly 6700-3300/3100 yr BC for Greece) when compared to other contemporaneous data from Bulgaria. In the pioneer study of Thomas (1981), archaeointensity data were derived from potsherds using a combination of methods, except the Thellier-Thellier one which proved to be unsuccessful at a first trial. The optimum protocol the author has applied is referred as ARM and SIRM corrections, and has been first cross-checked by application to samples of known intensity. No pTRM checks were performed since there was one single heating to impart a TRM. The author proceeded to several other tests, for example, partial refiring, thermomagnetic analysis etc. Anisotropy correction was not systematically applied since all remanences were given in the same direction as the NRM. In cases where this proved necessary, the author applied the correction proposed by Kono (1978). The cooling rate effect was not calculated since the sherds were left to cool within 7-10 hr, close to the natural rate. It should also be mentioned that in most cases only 1-2 specimens per horizon (but at least 3 per century) were considered. It is clear that modern quality criteria are not accomplished (see Genevey et al. 2008; Gómez-Paccard et al. 2012a; Pavón-Carrasco et al. 2014a for a detailed discussion on the different qualities of archaeointensity data). Nevertheless this study took into account all possible precautions at that time and we believe that the differences in intensity values observed may be also explained by the low number of specimens per horizon and the large age uncertainties in the TL datings. However, in two cases corresponding to ages comparable with our sites, a satisfactory convergence appears (table A1 in Tema \& Kondopoulou 2011):

(1) Minoan kilns in Crete, dated at 1345 and 1558 yr BC with age errors of 230-250 yr respectively and five specimens for each. The calculated intensities of $60.1 \pm 3.9$ and $60.5 \pm 7.3 \mu \mathrm{T}$, when relocated to a mean latitude between APK and ARH (our sites with comparable ages), yield values of 64.3 and $64.6 \mu \mathrm{T}$ respectively which, taking into account the error uncertainties, are reasonably close to the values for APK and ARH.

(2) Sitagroi (Northern Greece, close to the site DTc): sherds from the horizon dated at $2165 \mathrm{yr} \mathrm{BC}$ with error age of $100 \mathrm{yr}$. Even if only one sample is referred, the obtained value of $55 \pm 5.2$ $\mu \mathrm{T}$ is in very good agreement with the one obtained for the SKS collection revised in this study $(1925 \pm 125 \mathrm{yr} \mathrm{BC})$ of $53.5 \pm 4.1$ $\mu \mathrm{T}$ (Tema et al. 2012). Apart from the numerous data from Thomas (1981, 1983), several archaeointensity studies in Greece have been performed (for compilations see De Marco et al. 2008; Tema \& Kondopoulou 2011; Aidona \& Kondopoulou 2012; Tema et al. 2012; Fanjat et al. 2013; Kondopoulou et al. 2014, 2015). However, only 83 data correspond to the prehistoric period (before 1000/900 yr BC).

The new data obtained here (orange dots in Fig. 11) have been plotted together with all previous Greek archaeointensities. The high dispersion of the Greek archaeointensity data set is clear, further proving that some of the data might not be reliable. In an effort to further explore the reliability of the archaeointensity Greek data set we applied here the same protocol described in Pavón-Carrasco et al. (2014a) and we divided the data in two groups: high-quality (green dots in Fig. 11, corresponding to the A and B categories) and data corresponding to archaeointensities that can be considered as less reliable (grey dots in Fig. 11, C and D categories). A and $\mathrm{B}$ categories include data derived from at least 4 specimens and obtained from the original or derived Thellier-Thellier method including pTRM checks and TRM correction via TRM anisotropy tensor whatever the material analysed is, or data not including the TRM anisotropy correction but obtained from unlikely anisotropic objects (e.g. kilns, hearths, burnt soils). Considering the crucial effect of TRM anisotropy on potteries, we think that these criteria correspond to minimum quality standards for archaeointensity determinations in Greece, where the majority of data have been obtained from sherds and pottery fragments. The recently published Bulgarian Bayesian curve is also plotted in Fig. 11 (Kovacheva et al. 2014). Finally, we also plotted the results computed using three geomagnetic field models: the SHA.DIF.14k (Pavón-Carrasco et al. 2014b), the PFM9k.1 (Nilsson et al. 2014) and the CALS10K.10b (Korte et al. 2011).

Fig. 11 shows that when only high-quality Greek intensities are considered, the agreement between the Bayesian curve and Greek intensities is generally high, especially for the modern period where the Bulgarian curves are better defined. Some important discrepancies are observed for the prehistoric period, but as stated before, the lower number of reliable reference data for Greece at this period may explain these differences. The new archaeointensity for APK $(1364 \pm 99)$ fits very well with the high-quality intensity previously 


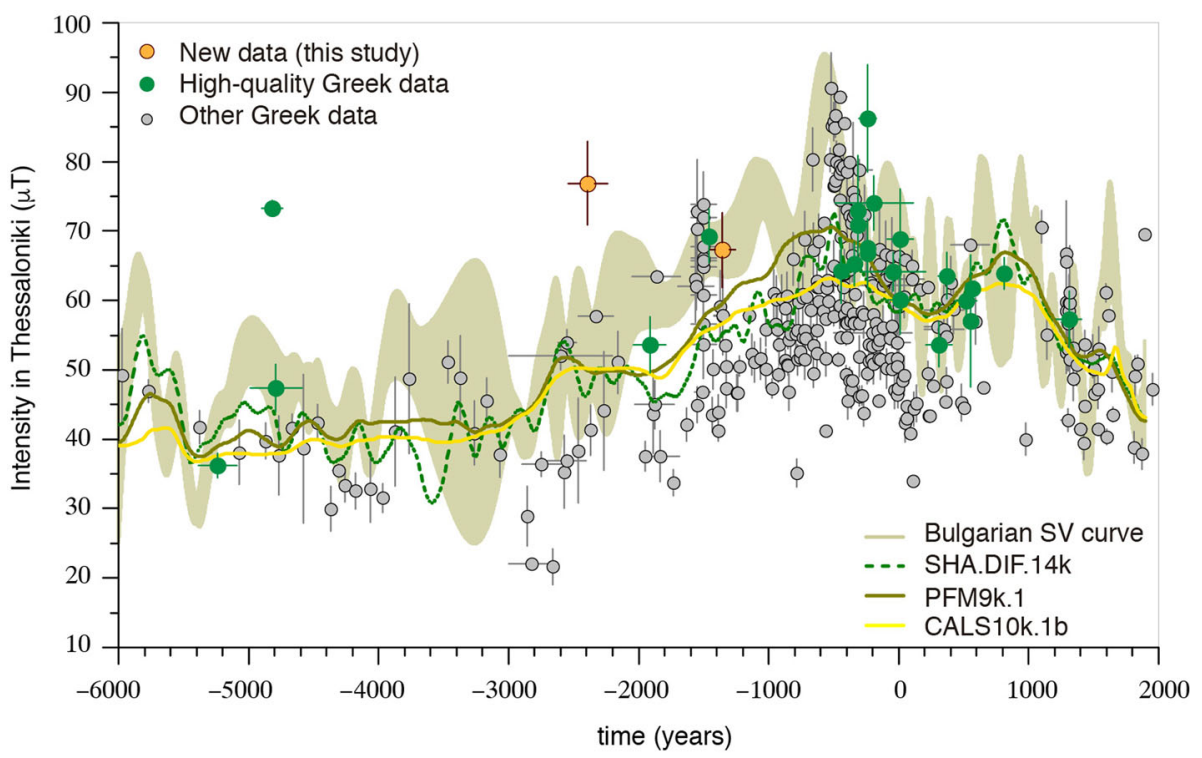

Figure 11. The new intensity results (in orange) are compared with previous high-quality archaeointensity data from Greece (in green) and with the Bulgarian Bayesian curve (Kovacheva et al. 2014) relocated to Thessaloniki coordinates. The other Greek data, which do not accomplish modern quality criteria are plotted in grey (see text for further details on the criteria used to perform the selection). The palaeointensity curves derived from the SHA.DIF.14k (Pavón-Carrasco et al. 2014b), the PFM9k.1 (Nilsson et al. 2014) and the CALS10K.10b (Korte et al. 2011) are also plotted.

obtained for the same period (ARH, Tema et al. 2012, green dot in Fig. 11) and with the Bulgarian curve. No previous archaeointensities are available for the same age than our new SKO intensity $(2400 \pm 159 \mathrm{yr} \mathrm{BC})$. The important divergence observed between SKO and the Bulgarian curve can be due to the gap in the Bulgarian database between 2500 and $1500 \mathrm{yr}$ BC. It should be noted, however, that the recently published curve for the Near East (Gallet et al. 2014) also indicates a decrease in the intensity from 2500 to $1500 \mathrm{BC}$, in agreement with the new data obtained here. The important differences observed between SKO and SKS (Table 3, Fig. 11) suggest rapid intensity fluctuations occurring in Greece during the third and second millennium BC. Rapid changes have been observed in other periods and regions and are quite usual in the history of the Earth's magnetic field (e.g. Gómez-Paccard et al. 2008, 2012a; Ben-Yosef et al. 2009; Shaar et al. 2011, 2015; Genevey et al. 2013; Hervé et al. 2013; Ertepinar et al. 2016). Gallet et al. (2014) have documented intensity maxima between 2600-2500 and 2300$2000 \mathrm{yr}$ BC in the near East and more recently, Ertepinar et al. (2016) documented an intensity maximum around $2400 \mathrm{yr}$ BC in Anatolia. A clear decrease in intensity values between 2400 BC and $2000 \mathrm{yr} \mathrm{BC}$ is also documented by Hammond (2014) on pottery samples from Cyprus, as well as Ben-Yosef et al. (2016). Our results are only indicative that such maxima might have occurred also during the Greek Bronze age since new, high-quality, data are clearly needed for further refining the Greek intensity fluctuations. Finally, we compared the Greek data with geomagnetic field models results (Fig. 11). It can be seen that the new data presented in this study (orange dots) do not fit well with the models. This suggests that the models pattern in Greece may be affected by some inaccurate data included in the databases used for computing them. This possibility has been already suggested in our previous studies (Gómez-Paccard et al. 2012a; Pavón-Carrasco et al. 2014a). The present results encourage us to continue with the acquisition of additional reliable intensities from this region, for further improving the regional Greek intensity curves and global geomagnetic field models.

\subsection{Implications for pottery selection procedures}

In order to exploit the causes of the failed experiments described above and use them for future research, we further investigated the information provided by the additional magnetic measurements and the impact of XRPD analysis to firing conditions.

No clear correlation could be established between the layered measurements of magnetization results and the success or failure of the Thellier experiment. Nevertheless, and since all specimens used for the archaeomagnetic study were at least $1 \mathrm{~cm}$ thick, the magnetic inhomogeneity observed between the external and the internal parts of the ceramics - a total thickness of $1.5 \mathrm{~cm}$-appears to be a frequent feature likely to affect the archaeointensity experiments. This is further reflected in the partially successful fragments which, though classified as such, provide intensity values only for one or two specimens (see Table 4). We note also that even a small amount of SD grains on the surface, is supporting a successful Thellier experiment. Therefore, the information provided by the above experiment can be considered as a strong evidence for intrafragment magnetic inhomogeneity but not as a pre-selection criterion.

The FORC diagrams provided valuable information on the magnetic mineralogy of the studied samples but did not establish a direct correlation with successful or failed intensity results. At a first approach this seems contradictory with the results of Carvallo et al. (2006) where a considerable improvement of pre-selection for Thellier experiments was demonstrated. This is certainly related to the fact that in this study, the main examined data set originated from basaltic lavas and only eight potsherds-from the historical periodwere included. It is obvious that our first trial to correlate such a screening with prehistoric pottery should be followed by more extended data sets, including various lithologies and archaeological periods.

The serious difficulty which raises from the heterogeneous clay pastes and concerns the use of twin specimens could be partly overcome by the use of powders rather than small chips, when and if this is possible. 
The XRPD results obtained on 22 specimens, which were also subjected to Thellier experiments (failed and successful), indicate medium to high firing temperatures for most of the studied sherds and constrain better their firing conditions. However, important differences on the firing temperatures within the same site are observed in several cases, reaching up to $400{ }^{\circ} \mathrm{C}$ (e.g. samples SKO5 and SKO3, Table 4). Differences in firing temperatures within the same production and their impact on archaeointensity calculations were suggested by Morales et al. (2011). At the fragment level, Gosselain (1992) reported evidence for large scale differentiation in their physical characteristics and Livingstone Smith (2001) documented, on the basis of a large data set from 80 firing structures, the extended diversity and complexity of firing technologies. Comparison between the mineralogical and the Thellier results, suggests that potential reasons for failed or low-success intensity results could be:

(1) The bad control of firing conditions such as the short firing duration which forms a sandwich structure (colour layers) in the ceramic body, which induces failure on archaeointensity determinations even if the content of magnetic minerals is sufficient (i.e. all samples-BSC from Vassili, samples SKS/SKO from Skala Sotiros, ARH-9 from Arhontiko).

The fast firing process, though the temperature reaches $800^{\circ} \mathrm{C}$, is not sufficient to lead in complete sintering across the ceramic body so that, in the core, the clay minerals and calcite can be preserved and the formation of oxide minerals is restricted to the surface layers. In other cases, the inhomogeneity which is depicted with the colour layers, is created either by the changing atmosphere during firing, from reducing to oxidizing (i.e. samples BSC) or by the presence of organic matters in the clay paste (i.e. samples SKS/SKO). Thus the crystallized magnetite and/or hercynite (spinel) remain in the core whilst on the surface it transforms to hematite (Maritan et al. 2006).

(2) The high content of quartz and feldspar grains as it is observed in samples from Skala Sotiros (SKS-SKO) in combination with the high calcite content and/or the presence of metamorphic rock fragments in the clay paste's composition, and the sandwich structure in many samples lead to failed intensity results. The high concentration of calcite $(\mathrm{CaO}>5$ wt per cent in clay paste) leads to the formation of Ca-Al-rich minerals (pyroxene, melilite) which incorporate the ferric/ferrous ions into their structure (Rathossi \& Pontikes $2010 \mathrm{~b}$ and references therein). This state has a negative effect on the crystallization of oxide minerals, particularly if the iron percentage in the clay paste is low, the oxide minerals are absent or, in spite of the high iron content in clay paste, the iron oxide concentration is low.

Because the XRPD analysis uses ceramic powder (better mixing of ceramic body) it is easier to detect the low content of oxide minerals, while the pieces used for the archaeointensity analysis, may not be representative in oxide mineral concentration.

(3) The high concentration of calcite or/and limestone fragments in clay paste plays a pivotal role for low-success/failed intensity results. As the firing temperature rises, above $750{ }^{\circ} \mathrm{C}$, a Ca-rich clay paste prevents the formation of magnetic minerals. All ferric or ferrous irons which are involved, participate in the structure of CaAl-rich mineral phases (i.e. ferrian aluminian diopside, gehlenite) rather than in the formation of iron oxide minerals (Rathossi \& Pontikes 2010a,b).
The results indicate that sites SKS/SKO (Thasos island) seem very unpromising for future archaeointensity studies in the area. The chemical and petrographic features of the prehistoric pottery in relation to the clays of the broader area were already investigated prior to the present study (Kilikoglou \& Tsolakidou 2012; Youni 2012) and indicated that the clays used for Skala Sotiros pottery (16 samples) are local, chemically homogeneous and distinct from the other sites in the north and western coast of the island.

The anisotropic clay paste revealed by petrographic examination of the same group indicates a firing temperature below $800{ }^{\circ} \mathrm{C}$ and is in accordance with the XRPD results of the present study.

Therefore, within Thasos island, at least one clay source could provide ceramics unsuitable for archaeointensity studies. Detailed description and potential reasons for the specific characteristics of Thasian ceramic products can be found in Supporting Information M2.

On the opposite, the absent or very low calcite content and the contribution of ophiolitic and volcanic rock fragments in clay paste of samples of sites ARH/APK (Vardar zone) suggest materials more suitable for future studies.

The potential of mineralogical methods is very promising and should be extended to the raw materials in the areas likely to provide the initial clays. For instance, in some samples from almost all sites (except Dikili Tash), the detection of preserved phyllosilicate minerals such as chlorite, smectite and mixed-layer minerals (Table 4, Fig. 10) which were included in their clay paste suggests the potential crystallization of iron oxides if only the firing temperature had exceed $700{ }^{\circ} \mathrm{C}$, leading to the dehydroxylation and decomposition of these minerals and the formation of the Fe-bearing minerals.

The relation of the baked clay products with the raw materials prevailing in a region and their suitability for archaeomagnetic studies has been first investigated by Jordanova et al. (2001). A further detailed study was presented by Kostadinova-Avramova \& Kovacheva (2013) who, using artificial samples from three different clay types in Bulgaria, performed numerous mineralogical and magnetic experiments in order to explain failed archaeointensity results on kiln materials. The main conclusion of the authors is that 'materials repeatedly heated in the antiquity are more appropriate for archaeointensity studies than single baked material'. We partly agree with this statement but we would like to point out that ceramics and pottery, when properly selected and studied, are also suitable candidates for archaeointensity studies. An additional argument towards this statement is that repeated heatings, even to high temperatures, do not guarantee success in an archaeointensity experiment as we have demonstrated in our comparative study on kilns (Kondopoulou et al. 2014).

\section{CONCLUSIONS}

Two new high-quality archaeointensity data for Greece are presented in this study. Thellier experiments have been accompanied by extensive magnetic mineralogy investigations. The new data contribute to a better monitoring of the Secular Variation during the Greek Bronze Age. One result (site APK) shows a very good agreement with previously published data from Greece while the second (site SKO) is clearly higher than the ones available for the same period. We note, however, that this time span (around $2400 \mathrm{yr} \mathrm{BC}$ ) lacks high-quality data and we suggest, after a closer examination of the source data (De Marco 2007), that the laboratory protocol used, age uncertainties, and the small number of specimens used to derive mean site intensities are possible factors for this divergence. 
Evidently, more data are necessary to better document this high intensity obtained which nevertheless shows the same tendency with Bronze age data from the Near East (e.g. Gallet et al. 2014, 2015). A combination of detailed magnetic mineralogy, X-ray diffraction and the geological context analysis on pottery from the two new sites is proposed here as well as on material from four Greek prehistoric sites previously studied.

Based on our results and on the thorough study of available literature on the subject we consider that proposing a pre-selection protocol for prehistoric ceramics needs a larger and more variable data set. Nevertheless our present experience allows us to suggest that the geological environment should be well examined, by applying magnetic and optical methods to the raw clays and possibly by retrieving information on magnetic properties of adjacent formations through existing palaeomagnetic studies in the area (Kondopoulou et al. 2016). Subsamples for various measurements should be taken in close proximity within the fragment and alternating field treatments should be eligible for a quick check of domain state, as proposed also by Carvallo et al. (2006). This approach allows the maximum use of the available archaeological material since magnetic experiments do not destroy the samples.

Finally, we stress the fact that pre-selection of fragments through a simple thermal demagnetization, though suggested in the past, has not been fully considered as an important first step to easily eliminate the samples carrying two components of magnetization. We highlight here this point since in many cases, secondary components are not connected only with cooking pots which can be discarded during sampling. Reheatings can be a consequence of burial when and if fire is set above any covered settlement. This heated surface can produce substantial thermal alterations of the archaeological burned artefacts buried in an earlier stage in the sequence. Apart from thermal alterations, the chronometric datings on such sites (e.g. luminescence) can be seriously affected, therefore the history of an archaeological settlement is crucial when both archaeomagnetic and/or luminescence studies are planned (Aldeias et al. 2016). This should be combined to the knowledge of local pottery firing technology since several practices include use of grog tempers (or chamotte). In fact either crushed pieces of previously burnt ceramics or crushed igneous rocks - granites or volcanics - are often included in the clay paste. This practice has been quite common in Bronze Age settlements in South Greece and Crete (Kiriatzi et al. 2016).

Consequences for archaeointensity studies have not been investigated yet and though the magnetic signal is probably not affected in the case of ceramic inclusions, it certainly is in the case of granite and volcanic ones (Rasmussen 2001).

Improving the outcome of archaeointensity studies on Greek prehistoric pottery/ceramic collections appears as an urgent target with a considerable potential. The extended archaeological information when available on prehistoric collections, together with accurate datings and existing analyses on the used clays, constitute an asset for the future development of this discipline.

\section{ACKNOWLEDGEMENTS}

The access to the two studied collections was ensured by Dr A. Georgiadou (Apsalos) and Dr Ch. Koukouli-Chrysanthaki (Skala Sotiros) who gave us all necessary information concerning the relevant excavations and the material selection. The corresponding permissions were provided by the Ephorates of Pella and KavalaThasos, respectively. We address our sincere thanks to all. Dr Y. Maniatis has kindly provided the detailed original datings for the
Apsalos site and Dr S. Papadopoulos the ones for Skala Sotiros. We would also like to thank Philippe Lanos (CNRS) for his help with the use of the Chronomodel software. Moreover, we acknowledge Dr N. C. Tsirliganis for providing access to the TL/OSL infrastructures at the Laboratory of Radiation Applications and Archaeological Dating, Athena-Research and Innovation Center in Xanthi, Greece. The INSTAP Center has substantially contributed to the funding of this research during the years 2012-2014. MGP acknowledges the Ramón y Cajal Program and the CGL2015-63888-R research project of the Spanish Ministry of Economy and Competitiveness. We would like to extend our warm thanks to our colleagues of the palaeomagnetic laboratory of Rennes (Géosciences-Rennes) where the archaeointensity measurements have been conducted. The manuscript has substantially benefited from the thorough comments of two anonymous reviewers and the editor Prof R. Holme.

\section{R E F E R E N C ES}

Aidona, E. \& Kondopoulou, D., 2012. First archaeomagnetic results and dating of neolithic structures in Northern Greece, Stud. Geophys. Geod., 56, 827-844.

Aitken, M.J., 1985. Thermoluminescence Dating, Academic Press.

Aitken, M.J., 1998. An Introduction to Optical Dating, Oxford Univ. Press. Aldeias, V., Dibble, H., Sandgathe, D., Goldberg, P. \& McPherron, S.J.P, 2016. How heat alters underlying deposits and implications for archaeological fire features: a controlled experiment, J. Arch. Sci., 67, 64-79.

Ballirano, P., De Vito, C., Medeghini, L., Mignardi, S., Ferrini, V., Matthiae, P., Bersani, D. \& Lottici, P., 2014. A combined use of optical microscopy, X-ray powder diffraction and micro-Raman spectroscopy for the characterization of ancient ceramic from Ebla (Syria), Ceram. Int., 40, 16 409-16 419.

Banerjee, D., Murray, A.S., Bøtter-Jensen, L. \& Lang, A., 2001. Equivalent dose estimation using a single aliquot of polymineral fine grains, Radiat. Meas., 33, 73-94.

Belshé, J.C., Cook, K. \& Cook, R.M., 1963. Some archaeomagnetic results from Greece, Ann. Br. Sch. Athens, 58, 8-13.

Ben-Yosef, E., Tauxe, L., Levy, T.E., Shaar, R., Ron, H. \& Najjar, M., 2009. Geomagnetic intensity spike recorded in high resolution slag deposit in Southern Jordan, Earth planet. Sci. Lett., 287(3-4), 529-539.

Ben-Yosef, E., Gidding, A., Tauxe, L., Davidovich, U., Najjar, M. \& Levy, T.E., 2016. Early Bronze Age copper production systems in the northern Arabah Valley: new insights from archaeomagnetic study of slag deposits in Jordan and Israel, J. Arch. Sci., 72, 71-84.

Bøtter-Jensen, L., Bulur, E., Duller, D.A.T. \& Murray, A.S., 2000. Advances in luminescence instrument systems, Radiat. Meas., 32, 523-528.

Brown, M.C., Donadini, F., Korte, M., Nilsson, A., Korhonen, K., Lodge, A., Lengyel, S.N. \& Constable, C.G., 2015. GEOMAGIA50.v3: 1. General structure and modifications to the archeological and volcanic database, Earth Planets Space 67, 83, doi:10.1186/s40623-015-0232-0.

Carvallo, C., Roberts, A., Leonhardt, R., Laj, C., Kissel, C., Perrin, M. \& Camps, P., 2006. Increasing the efficiency of paleointensity analyses by selection of samples using first-order reversal curve (FORC) diagrams, J. geophys. Res., 111, B12103, doi:10.1029/2005JB004126.

Catanzariti, G., Gómez-Paccard, M., McIntosh, G., Pavon-Carrasco, F.J., Chauvin, A. \& Osete, M.L., 2012. New archaeomagnetic data recovered from the study of Roman and Visigothic remains from central Spain (3rd-7th centuries), Geophys. J. Int., 188, 979-993.

Chrysostomou, A., Georgiadou, A., Poloukidou, X. \& Prokopidou, A. 2002. Excavations on the Apsalos-Aridaia provincial road in 2000, AEMTH, 14, 491-505 (in Greek with English abstract).

Coe, R.S., Grommé, S. \& Mankinen, A., 1978. Geomagnetic paleointensities from radiocarbon-dated lava flows on Hawai and the question of the Pacific non dipole low, J. geophys. Res., 83, 1740-1756.

Compana, J.M., Cabeza, A., Aranda, M.A.G. \& León-Reina, L., 2014. The Baetican workshops: a starting point to study Terra Sigillata Hispanica, J. Arch. Sci., 45, 26-35. 
Cui, Y. \& Verosub, K., 1995. A mineral magnetic study of some pottery samples: possible implications for sample selection in archaeointensity studies, Phys. Earth planet. Inter., 91, 261-171.

Cui, Y., Verosub, K., Roberts, A. \& Kovacheva, M., 1997. Mineral magnetic studies of archaeological samples: implications for sample selection for paleointensity determinations, J. Geomagn. Geoelectr., 49, 567-585.

Day, R., Fuller, M.D. \& Schmidt, V.A., 1977. Hysteresis parameters of titanomagnetites: grain size and composition dependence, Phys. Earth. planet. Inter., 13, 260-167.

De Bonis, A., Cultrone, G., Grifa, C., Langella, A. \& Morra, V. 2014. Clays from the Bay of Naples (Italy): new insight on ancient and traditional ceramics, J. Eur. Ceram. Soc., 34, 3229-3244.

De Groot, L.V., Biggin, A.J., Dekkers, M.J., Langereis, C.G. \& HerreroBarvera, E., 2013. Rapid regional perturbations to the recent global geomagnetic decay revealed by a new Hawaiian record, Nat. Commun., 4, 2727, doi:10.1038/ncomms3727.

Deliopoulos, G., 2014. Ceramic production, organization and functioning of habitation levels I-III from Arhontiko (Yannitsa)-Greece, $P h D$ thesis, Aristotle University of Thessaloniki, Greece (in Greek).

De Marco, E., 2007. Complete magnetic and archaeomagnetic measurements in archaeological sites: contribution to the SVC for Greece, $P h D$ thesis, Aristotle University of Thessaloniki, Thessaloniki, Greece.

De Marco, E.D., Spatharas, V., Gómez-Paccard, M., Chauvin, A. \& Kondopoulou, D., 2008. New archaeointensity results from archaeological sites and variation of the geomagnetic field intensity for the last 7 millennia in Greece, Phys. Chem. Earth, 33, 578-595.

De Marco, E.D., Tema, E., Lanos, P.H. \& Kondopoulou, D., 2014. An updated catalogue of Greek archaeomagnetic data for the last 4500 years and a directional secular variation curve, Stud. Geophys. Geod., 58, 127-147.

De Souza Santos, H \& Yada, K., 1988. Thermal transformation of talc as studied by electron-optical methods, Clays Clay Miner., 36(4), 289-297.

Dunlop, D.J., 2002. Theory and application of the Day plot $\left(M_{\mathrm{rs}} / M_{\mathrm{S}}\right.$ versus $\left.H_{\mathrm{cr}} / H_{\mathrm{c}}\right)$. 1. Theoretical curves and tests using titanomagnetite data, J. geophys. Res., 107, 2056-2077.

Egli, R., 2013. VARIFORC: an optimized protocol for calculating nonregular first-order reversal curve (FORC) diagrams, Glob. Planet. Change, 110, 302-320.

Ertepinar, P., Langereis, C.G., Biggin, A.J., de Groot, L.V., Kulakoglu, F., Omura, S. \& Süel, A., 2016. Full vector archaeomagnetic records from Anatolia between 2400 and 1350 BCE: implications for geomagnetic field models and the dating of fires in antiquity, Earth planet. Sci. Lett., 434, $171-186$.

Fanjat, G., Aidona, E., Kondopoulou, D., Camps, P., Rathossi, C. \& Poidras, T., 2013. Archaeointensities in Greece during the Neolithic period: new insights into material selection and secular variation curve, Phys. Earth planet. Inter., 215, 29-42.

Gallet, Y., D’Andrea, M., Genevey, A., Pinnock, F., Le Goff, M. \& Matthiae, P., 2014. Archaeomagnetism at Ebla (Tell Mardikh, Syria). New data on geomagnetic field intensity variations in the Near East during the Bronze Age, J. Arch. Sci., 42, 295-304.

Gallet, Y. et al., 2015. New Late Neolithic (c. 7000-5000 BC) archeointensity data from Syria. Reconstructing 9000 years of archeomagnetic field intensity variations in the Middle East, Phys. Earth planet. Inter, 238, 89-103.

Genevey, A., Gallet, Y., Constable, C., Korte, M. \& Hulot, G., 2008. ArcheoInt: An upgraded compilation of geomagnetic field intensity data for the past ten millennia and its application to recovery of the past dipole moment, Geochem. Geophys. Geosyst., 9, Q04038, doi:10.1029/2007GC001881.

Genevey, A., Gallet, Y., Thebault, E., Jesset, S. \& Le Goff, M., 2013. Geomagnetic field intensity variations in Western Europe over the past 1100 years, Geochem. Geophys. Geosyst., 14, 2858-2872.

Genevey, A., Gallet, Y., Jesset, S., Thebault, E., Bouillon, J., Leferve, A. \& Le Goff, M., 2016. New archeointensity data from French Early Medieval pottery production (6th-10th century AD). Tracing 1500 years of geomagnetic field intensity variations in Western Europe, Phys. Earth planet. Inter., 257, 205-219.

Germain-Vallée, C., Prevost-Dermarkar, S. \& Lespez, L., 2011. Sampling strategies and their application to Neolithic "Earth Construction" com- bustion structures at the Dikili-Tash Site (Greece) based on a micromorphological study, Archeo Sci., revue d' Archeometrie, 35, 41-63.

Gómez-Paccard, M., Chauvin, A., Lanos, P., Thiriot, J. \& Jimenez-Castillo, P., 2006. Archeomagnetic study of seven contemporaneous kilns from Murcia (Spain), Phys. Earth planet. Inter, 157, 16-32.

Gómez-Paccard, M., Chauvin, A., Lanos, P. \& Thiriot, J., 2008. New archeointensity data from Spain and the geomagnetic dipole moment in western Europe over the past 2000 years, J. geophys. Res., 113, B09103, doi:10.1029/2008JB005582.

Gómez-Paccard, M. et al., 2012a. Improving our knowledge of rapid geomagnetic field intensity changes observed in Europe between 200 and 1400 AD, Earth Planet. Sci. Lett., 355-356, 131-143.

Gómez-Paccard, M., McIntosh, G., Chauvin, A., Beamud, E., PavónCarrasco, F.J. \& Thiriot, J., 2012b. Archaeomagnetic and rock magnetic study of six kilns from North Africa (Tunisia and Morocco), Geophys. $J$. Int., 189, 169-186

Gómez-Paccard, M., Osete, M.L., Chauvin, A., Pavón-Carrasco, F.J., Pérez, M., Jiménez, P. \& Lanos, P., 2016. New constraints on the most significant paleointensity change in Western Europe over the last two millennia. A non-dipolar origin?, Earth Planet. Sci. Lett., 454, 55-64.

Gosselain, O.P., 1992. Bonfire of the Enquiries. Pottery firing temperatures in archaeology: what for?, J. Arch. Sci., 19, 243-259.

Grapes, R.H., 2006. Pyrometamorphism, Springer.

Grim, R.E., 1968. Clay Mineralogy, 2nd edn, McGraw-Hill Book Co.

Hammond, M.L., 2014. The use of Archaeomagnetism to answer Archaeological and Geomagnetic questions with particular focus on determination of the strength of the Geomagnetic field in the Middle east during the Bronze age, PhD thesis, University of Liverpool, pp. 260.

Hein, A. \& Kilikoglou, V., 2012. Cera-DAT-Prototype of a web-based relational database for archaeological ceramics, Archaeometry, 54, 230243.

Hervé, G., Chauvin, A. \& Lanos, P., 2013. Geomagnetic field variations in Western Europe from 1500 BC to 200 AD. Part II: New intensity secular variation, Phys. Earth planet. Inter., 218, 51-65.

Holakooei, P., Tessari, U., Verde, M. \& Vaccaro, C., 2014. A new look at XRD patterns of archaeological ceramic bodies, J. Therm. Anal. Calorimetry, 118(1), 165-176.

Issi, A., Kara, A. \& Oğuz Alp, A., 2011. An investigation of Hellenistic period pottery production technology from Harabebezikan/Turkey, Ceram. Int., 37(7), 2575-2582.

Jordanova, N., Petrovsky, E. \& Kovacheva, M., 1997. Preliminary rock magnetic study of archaeomagnetic samples from Bulgarian sites of BC time, J. Geomagn. Geoelectr., 49, 543-566.

Jordanova, N., Petrovsky, E., Kovacheva, M. \& Jordanova, D., 2001. Factors determining magnetic enhancement of burnt clay from archaeological sites, J. Arch. Sci., 28, 1137-1148.

Kilikoglou, V. \& Tsolakidou, A., 2012. Chemical analyses of Thasian clays and prehistoric pottery from Limenaria and neighboring site, in Ten Years of Excavations in the Prehistoric Settlement of Limenaria, Thasos, Proceedings, Thasos, July 11, 2003, pp. 155-171, eds Papadopoulos, S. \& Malamidou, D. (in Greek with English abstract).

Kiriatzi, E., Pentedeka, A., Müller, N.S. \& Gait, J., 2016. Pots within pots: the practice of grog-tempering and social networks in and around the Aegean towards the end of Neolithic and the beginning of Bronze Age, in 41st Symposium on Archaeometry, 15-21 May 2016, Kalamata, Greece, Book of Abstracts.

Kirschvink, J.K., 1980. The least-square line and plane and the analysis of palaeomagnetic data, Geophys. J. R. astron. Soc., 62, 699718.

Kloprogge, J.T. \& Frost, R.L., 2000. Thermal decomposition of Ferrian chamosite: an infrared emission spectroscopic study, Contrib. Miner. Petrol., 138, 59-67.

Kondopoulou, D., Zananiri, I., Rathossi, C.H., De Marco, E., Spatharas, V. \& Hasaki, E., 2014. An archaeometric and archaeological approach to Hellenistic-early Roman ceramic workshops in Greece: contribution to dating, Radiocarbon, 56, S27-S38.

Kondopoulou, D., Aidona, E., Ioannidis, N., Polymeris, G.S. \& Tsolakis, S., 2015. Archaeomagnetic study and thermoluminescence dating of 
Protobyzantine kilns (Megali Kypsa, North Greece), J. Arch. Sci. Rep., 2, 156-168.

Kondopoulou, D., Zananiri, I., Aidona, E. \& Rathossi, Ch., 2016. Archaeomagnetic research through the eyes of palaeomagnetists: possible impact on the study of baked clays in various geological environments in Greece, in 41st Symposium on Archaeometry, 15-21 May 2016, Kalamata, Greece, Book of Abstracts.

Kono, M., 1978. Reliability of palaeointensity methods using alternating field demagnetization and anhysteretic remanence, Geophys. J. R. astron. Soc., 54, 241-261.

Korte, M., Constable, C., Donadini, F. \& Holme, R., 2011. Reconstructing the Holocene geomagnetic field, Earth planet. Sci. Lett., 312, 497-505.

Kostadinova-Avramova, M. \& Kovacheva, M., 2013. The magnetic properties of baked clays and their implications for past geomagnetic field intensity determinations, Geophys. J. Int., 195, 1534-1550.

Koukouli-Chrysanthaki, C.H., 1989. An early Bronze age settlement in Skala Sotiros, Thasos, AEMTH 3, 507-512 (in Greek).

Koukouli-Chrysanthaki, Ch. \& Papadopoulos, S., 2016. The island of Thasos from the Neolithic to the Early Bronze age. Excavation data and absolute dates, in The Human face of Radiocarbon, pp. 340-358, TMO 69, ed. Tsirtsoni, Z., Maison de l'Orient et de la Mediterranee.

Koukouli-Chysanthaki, Ch., Malamidou, D., Papadopoulos, S. \& Maniatis, Y., 2008. The younger phase of early bronze age at Thasos: new data, In International Conference The Early Bronze Age in the Aegean: New data, pp. 11-14, eds Doumas, C.H., Giannikouri, A. \& Kouka, O., Archaeological Institute for Aegean Studies (in Greek, in press).

Kovacheva, M., 1969. Inclination of the Earth's Magnetic field during the last 2000 years in Bulgaria, J. Geomagn. Geoelectr., 21(3), 563-578.

Kovacheva, M., Kostadinova-Avramova, M., Jordanova, N., Lanos, P. \& Boyadziev, Y., 2014. Extended and revised archaeomagnetic database and secular variation curves from Bulgaria for the last eight millennia, Phys. Earth planet. Inter., 236, 79-84.

Kramar, S., Lux, J., Mladenović, A., Pristacz, H., Mirtič, B., Sagadin, M. \& Rogan-Šmuc, M. 2012. Mineralogical and geochemical characteristics of Roman pottery from an archaeological site near Mošnje (Slovenia), Appl. Clay Sci., 57, 39-48.

Lanos, P. \& Philippe, A., 2015. Event model: a robust Bayesian tool for chronological modeling, $H A L$.

Lanos, P. \& Philippe, A., 2017. Hierarchical Bayesian modeling for combining Dates in archaeological contexr, J. de la Societe Francaise de Statistique (in press).

Lanos, P., Philippe, A., Lanos, H. \& Dufresne, P., 2015. 'Chronomodel: chronological modelling of Archaeological data using Bayesian statistics. (release 1.1 January 2015; release 1.5 March 2016)'. Available at: http://www.chronomodel.fr.

Leonhardt, R., Heunemann, C. \& Krasa, D., 2004. Analyzing absolute paleointensity determinations: acceptance criteria and the software ThellierTool4.0, Geochem. Geophys. Geosyst., 5, Q12016, doi:10.1029/2004GC000807.

Livingstone Smith, A., 2001. Bonfire II: the return of pottery firing temperatures, J. Arch. Sci., 28, 991-1003.

Lowrie, W., 1990. Identification of ferromagnetic minerals in a rock by coercivity and unblocking temperature properties, Geophys. Res. Lett., 17, 159-162.

Mackenzie, R.C., 1957. Differential Thermal Investigation of Clays, Mineralogical Society.

Maniatis, Y., 2014. Radiocarbon dating of the major cultural changes in Prehistoric Macedonia: recent developments, in A Century of Research in Prehistoric Macedonia 1912-2012, International Conference Proceedings, Thessaloniki, 22-24 November, 2012, pp. 205-223, eds Stefani, E., Merousis, N. \& Dimoula, A. Archaeological Museum of Thessaloniki.

Maniatis, Y., Nerantzis, N. \& Papadopoulos, S., 2015. Radiocarbon dating of Aghios Antonios, Potos, and intersite chronological variability in South Thasos, Greece, Radiocarbon, 57(5), 807-823.

Maritan, L., Nodari, L., Mazzoli, C., Milano, A. \& Russo, U. 2006. Influence of firing conditions on ceramic products: experimental study on clay rich inorganic matter, Appl. Clay Sci., 31(1-2), 1-15.
Matau, F., Nica, V., Postolache, P., Ursachi, I., Cotiuga, V. \& Stancu, A., 2013. Physical study of the Cucuteni pottery technology, J. Arch. Sci., 40(2), 914-925.

Moore, D.M. \& Reynolds, R.C., Jr, 1989. X-ray Diffraction and the Identification and Analysis of Clay Minerals, Oxford Univ. Press.

Morales, J., Goguitchaichvili, A., Aguilar-Reyes, B., Pineda-Duran, M., Camps, P., Carvallo, C. \& Calvo-Rathert, M., 2011. Are ceramics and bricks reliable absolute geomagnetic intensity carriers?, Phys. Earth plannet. Inter, 187(3-4), 310-321.

Moroni, B. \& Conti, C., 2006. Technological features of Renaissance pottery from Deruta (Umbria, Italy): an experimental study, Appl. Clay Sci., 33(34), 230-246.

Murad, E. \& Wagner, U., 1998. Clays and clay minerals: the firing process, Hyperfine Interact., 117, 337-356.

Murray, A.S. \& Wintle, A.G., 2000. Luminescence dating of quartz using an improved single aliquot regenerative dose protocol, Radiat. Meas., 32, $57-73$.

Nodarou, E., 2010. Chapter 1: Petrographic analysis of the LM III pottery assemblage, in Mochlos IIB. Period IV. The Mycenaean Settlement and Cemetery. The Pottery, pp. 3-14, ed. Smith, R.A.K., INSTAP Academic Press.

Nilsson, N., Holme, R., Korte, M., Suttie, N. \& Hill, M., 2014. Reconstructing Holocene geomagnetic field variation: new methods, models and implications, Geophys. J. Int., 198, 229-248.

Pavón-Carrasco, F.J., Gómez-Paccard, M., Hervé, G., Osete, M.L. \& Chauvin, A., 2014a. Intensity of the geomagnetic field in Europe for the last $3 \mathrm{ka}$ : influence of data quality on geomagnetic field modeling, Geochem. Geophys. Geosyst., 15, doi:10.1002/2014GC005311.

Pavón-Carrasco, F.J., Osete, M.L., Torta, J.M. \& De Santis, A., 2014b. A geomagnetic field model for the Holocene based on archaeomagnetic and lava flow data, Earth planet. Sci. Lett., 388, 98-109.

Pick, T. \& Tauxe, L., 1993. Holocene paleointensities: Thellier experiment on submarine basaltic glass from the East Pacific Rise, J. geophys. Res. 98, 17 949-17964.

Prevot, M., Mankinen, E.A., Coe, R.S. \& Gromme, C.S., 1985. The Steens Mountain (Oregon) geomagnetic polarity transition. 2. Field intensity variations and discussion of reversal models, J. geophys. Res., 90, $10417-10448$.

Rasmussen, K.L., 2001. Focus: provenance of ceramics revealed by magnetic susceptibility and thermoluminescence, J. Arch. Sci., 28, 451-456.

Rathossi, C. \& Pontikes, Y., 2010a. Effect of firing temperature and atmosphere on ceramics made of NW Peloponnese clay sediments. Part I: Reaction paths, crystalline phases, microstructure and colour, J. Eur. Ceram. Soc., 30, 1841-1851.

Rathossi, C. \& Pontikes, Y., 2010b. Effect of firing temperature and atmosphere on ceramics made of NW Peloponnese clay sediments: Part II. Chemistry of pyrometamorphic minerals and comparison with ancient ceramics, J. Eur. Ceram. Soc., 30, 1853-1866.

Rathossi, C., Katagas-Tsolis, P. \& Katagas, C., 2010. Thermal behaviour of 'metamorphic vermiculite' in Ca-rich ancient ceramic sherds and experimental ceramics, Mineral. Magn., 74(4), 747-771.

Reimer, P.J. et al., 2013. IntCal13 and Marine13 Radiocarbon Age Calibration Curves 0-50,000 Years cal BP, Radiocarbon, 55(4), 18691887.

Reingruber, A. \& Thissen, L., 2009. Depending on 14C Data: chronological frameworks in the Neolithic and Chalcolithic of Southeastern Europe, Radiocarbon, 51(2), 751-770.

Roberts, A.P., Pike, C.R. \& Verosub, K.L., 2000. First-order reversal curve diagrams: a new tool for characterizing the magnetic properties of natural samples, J. geophys. Res., 105, 28 461-28 475 .

Schwedt, A., Mommsen, H., Zacharias, N., Buxeda, I. \& Garrigos, J., 2006. Analcime crystallization and compositional profiles-comparing approaches to detect post-depositional alterations in archaeological pottery, Archaeometry, 48(2), 237-251.

Shaar, R., Ben-Yosef, E., Ron, H., Tauxe, L., Agnon, A. \& Kessel, R., 2011. Geomagnetic field intensity: how high can it get? How fast can it change? Constraints from Iron Age copper slag, Earth planet. Sci. Lett., 301(1-2), 297-306. 
Shaar, R., Tauxe, L., Ben-Yosef, E., Kassianidou, V., Lorentzen, B., Feinberg, J.M. \& Levy, T.E., 2015. Decadal scale variations in geomagnetic field intensity from ancient Cypriot slag mounds, Geochem. Geophys. Geosyst., 16, doi:10.1002/2014GC005455.

Shoval, S., Gaft, M., Beck, P. \& Kirsh, Y., 1993. The thermal behaviour of limestone and monocrystalline calcite temper during firing and their use in ancient vessels, J. Therm. Anal., 40(1), 263-273.

Tema, E. \& Kondopoulou, D., 2011. Secular variation of the Earth's magnetic field in the Balkan region during the last eight millennia based on archaeomagnetic data, Geophys. J. Int., 186, 603-614.

Tema, E., Gómez-Paccard, M., Kondopoulou, D. \& Almar, Y., 2012. Intensity of the Earth's magnetic field in Greece during the last five millennia: new data from Greek pottery, Phys. Earth planet. Inter, 202/203, 14-26.

Thellier, E. \& Thellier, O., 1959. Sur l'intensité du champ magnétique terrestre dans le passé historique et géologique, Ann. Géophys., 15, 285376.

Thomas, R.C., 1981. Archaeomagnetism of Greek pottery and Cretan kilns, $\mathrm{PhD}$ thesis. Edinburgh University, vol. 1, 2.

Thomas, R.C., 1983. Summary of prehistoric archaeointensity data from Greece and eastern Europe, In Geomagnetism of Baked Clays and recent Sediments, pp. 117-122, Creer, K.M., Tucholka, P. \& Barton, C.E., Elsevier.

Tsirtsoni, Z., 2016. The chronological framework in Greece and Bulgaria between the Late 6th and the Early 3rd millennium BC and the "Balkans 4000" project, in The Human Face of Radiocarbon, pp. 340-358, TMO 69, ed. Tsirtsoni, Z,Maison de l'Orient et de la Mediterranee.

Urem-Kotsou, D., 2016. Changing pottery technology in the later Neolithic in North Greece, in Human Mobility and Technological Transfer in the Prehistoric Mediterranean, eds Knappett, C. \& Kiriatzi, E.,Cambridge Univ. Press.

Walker, M., 2005. Quaternary Dating Methods, Wiley.

Wardle, K., Highham, T. \& Kromer, B., 2014. Dating the End of the Greek Bronze age: a robust radiocarbon-Based chronology from Assitos Toumba, PLoS One, 9(9), e106672.1.

Youni, P., 2012. Petrographic analysis of pottery from Limenaria (Thasos), in Ten years of Excavations in the Prehistoric Settlement of Limenaria, Thasos, Proceedings, Thasos, July 11, 2003, pp. 129-147, eds Papadopoulos, S. \& Malamidou, D. (in Greek with English abstract).

\section{SUPPORTING INFORMATION}

Supplementary data are available at $G J I$ online.

Suppl_mater_M1: Description of the re-evaluated sites. Suppl_mater_M2: Geology and ceramic production in Thasos. Table S1. Archaeointensity results for the characteristic components at specimen level.

Figure S1. Layered magnetization measurements for sample APK1. The magnetic content is homogeneous containing either hematite, or small amounts of MD magnetite.

Figure S2. Layered magnetization measurements for sample APK10. The magnetic content is homogeneous containing big amounts of MD magnetite.

Figure S3. Layered magnetization measurements for sample ARH1. Possibly varnished surface containing SD magnetite while less MD magnetite is observed in depth.

Figure S4. Layered magnetization measurements for sample ARH3. The magnetic content is homogeneous containing MD magnetite.

Figure S5. Layered magnetization measurements for sample ARH5. The magnetic content is homogeneous with high amounts of MD magnetite.

Figure S6. Layered magnetization measurements for sample BSc13. Big amounts of SD magnetite are found on surface, and MD magnetite in depth.
Figure S7. Layered magnetization measurements for sample BSc25-3. The magnetization is not homogeneous as different layers contain SD magnetite in different percentage.

Figure S8. Layered magnetization measurements for sample DTc3. The magnetization is homogeneous with high content of MD magnetite.

Figure S9. Layered magnetization measurements for sample SKO2 showing a possible insufficient heating.

Figure S10. Layered magnetization measurements for sample SKO16. Possibly varnished surface or with different thermal treatment. Small amounts of MD magnetite or hematite.

Figure S11. Layered magnetization measurements for sample SKO31. The magnetization is homogeneous due to SD magnetite.

Please note: Oxford University Press is not responsible for the content or functionality of any supporting materials supplied by the authors. Any queries (other than missing material) should be directed to the corresponding author for the paper.

\section{APPENDIX: LUMINESCENCE DATING MEASUREMENTS}

Luminescence dating works on the principle that materials containing naturally occurring radioactive isotopes, such as natural uranium, thorium ${ }^{232} \mathrm{Th}$, rubidium ${ }^{87} \mathrm{Rb}$ and potassium ${ }^{40} \mathrm{~K}$, or which lie in close proximity to other materials containing these radioactive elements, are subject to low levels of radiation (Walker 2005). These naturally occurring minerals act as natural dosimeters and preserve a record of irradiation dose received through time (Aitken 1985, 1998). The accumulated dose is stored by means of trapped charge in crystal defects, being stable over long periods of time but can be released either by heating (TL) or exposure to light (OSL).

This is the process of recombination over which a fraction of the trapped charge releases energy in the form of light. The brightness of the luminescence signal reflects the total amount of trapped charge; thus, it also reflects the time subjected to irradiation. When dating kilns, any prior trapped charge is usually emptied by prolonged heating, every time that the material is subjected to firing; thus, electrons are evicted and traps are emptied. In that case, the material is said to be totally zeroed. In a nutshell, archaeomagnetic and luminescence dating techniques date exactly the same event, this being the last heating of the artefacts at high temperature.

Towards the direction of age determination, the knowledge of two different physical quantities is requested; the total accumulated dose during the past, termed as palaeodose or equivalent dose (hereafter ED in units of Gy), as well as the rate at which this energy-dose is accumulated, termed as dose rate (hereafter DR in units of Gy $\mathrm{ky}^{-1}$ ). The age is expressed as the ratio of these two later quantities, that is, the palaeodose over the dose rate.

In the SAR OSL technique the signal intensity of an aliquot of extracted grains (called natural OSL) is recorded; then the same aliquot is subjected to a series of subsequent laboratory irradiations with a calibrated radiation source and OSL measurements.

Each disc was exposed to infrared radiation for $100 \mathrm{~s}$ at $50^{\circ} \mathrm{C}$ before the laser stimulation, in order to reduce the malign influence of feldspars grain to the signal. The procedure is similar to the double SAR procedure of Banerjee et al. (2001), containing additional SAR steps in order to minimize the need for chemical separation. The dose rate is calculated based on the decay of naturally occurring radionuclides inside the clay matrix, that is, ${ }^{232} \mathrm{Th},{ }^{40} \mathrm{~K}$, and natural $\mathrm{U}$. Uranium and thorium concentrations were estimated using thick 
source alpha counting, while the potassium concentration by using micro-XRF. Table 2 presents an outline of the physical quantities required in order to perform age assessment, along with the corresponding yielded ages. In the present case a RIS $\varnothing$ TL/OSL reader (model TL/OSL-DA-15), equipped with a high-power blue LED light source, an infrared solid-state laser, a $0.106 \mathrm{~Gy} \mathrm{~s}^{-1}{ }^{90} \mathrm{Sr} /{ }^{90} \mathrm{Y}$ $\beta$-ray source and an EMI 9635QA PM Tube (Bøtter-Jensen et al. 2000) were used.

All OSL measurements were performed at the continuous wave configuration (CW-OSL), for $100 \mathrm{~s}$ at $125^{\circ} \mathrm{C}$ with the LED power held at 90 per cent power at $125{ }^{\circ} \mathrm{C}$, using a Hoya U-340 filter $(270-380 \mathrm{~nm})$. 